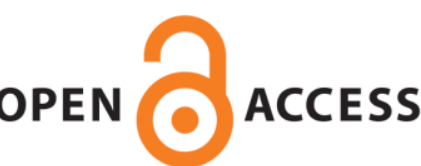

UWS Academic Portal

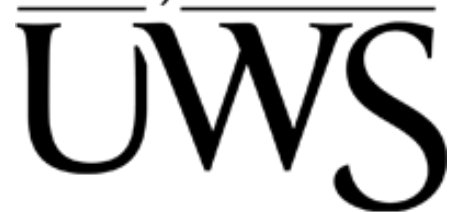

\title{
Evaluation of heavy metals stability and phosphate mobility in the remediation of sediment by calcium nitrate
}

Zhou, Jizhi; Zhang, Mingqi; Ji, Meiting; Wang, Zhenghua; Hou, Hao; Zhang, Jia; Huang, Xin; Hursthouse, Andrew; Qian, Guangren

Published in:

Water Environment Research

DOI:

10.1002/wer.1297

Published: 31/07/2020

Document Version

Peer reviewed version

Link to publication on the UWS Academic Portal

Citation for published version (APA):

Zhou, J., Zhang, M., Ji, M., Wang, Z., Hou, H., Zhang, J., Huang, X., Hursthouse, A., \& Qian, G. (2020).

Evaluation of heavy metals stability and phosphate mobility in the remediation of sediment by calcium nitrate.

Water Environment Research, 92(7), 1017-1026. https://doi.org/10.1002/wer.1297

\section{General rights}

Copyright and moral rights for the publications made accessible in the UWS Academic Portal are retained by the authors and/or other copyright owners and it is a condition of accessing publications that users recognise and abide by the legal requirements associated with these rights.

Take down policy

If you believe that this document breaches copyright please contact pure@uws.ac.uk providing details, and we will remove access to the work immediately and investigate your claim. 
"This is the peer reviewed version of the following article: Zhou, J., Zhang, M., Ji, M., Wang, Z., Hou, H., Zhang, J., Huang, X., Hursthouse, A., \& Qian, G. (2020). Evaluation of heavy metals stability and phosphate mobility in the remediation of sediment by calcium nitrate. Water Environment Research, 92(7), 1017-1026, which has been published in final form at https://doi.org/10.1002/wer.1297. This article may be used for non-commercial purposes in accordance with Wiley Terms and Conditions for Use of Self-Archived Versions."

https://authorservices.wiley.com/author-resources/Journal-Authors/licensing/selfarchiving.html 


\title{
Evaluation of heavy metals stability and phosphate mobility in the remediation of sediment by calcium nitrate
}

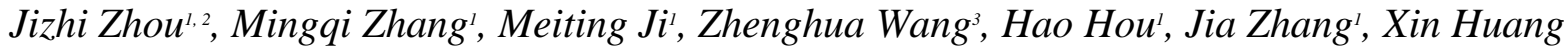
*,, Andrew Hursthouse ${ }^{3,4}$ and Guangren Qian ${ }^{1}$

1. School of Environmental and Chemical Engineering, Shanghai University, Shanghai 200444, China

2. School of Economics, Shanghai University, Shanghai 200444, China

3. Hunan Provincial Key Laboratory of Shale Gas Resource Exploitation, Hunan University of Science \&Technology, Xiangtan, 411201, Hunan, China

4. School of Science \& Sport, University of the West of Scotland, Paisley PA1 2BE, UK

* Corresponding author:

*Tel: 086-021-66137748; Fax: 021-66137761; Email: huangxin2008@ shu.edu.cn

\begin{abstract}
The injection of oxidants is one of the useful remediation technology for eliminating hydrogen sulfide $\left(\mathrm{H}_{2} \mathrm{~S}\right)$ and ammonia $\left(\mathrm{NH}_{3} / \mathrm{NH}_{4}^{+}\right)$in aquatic sediments. In the current work, the impact of calcium nitrate injection on the release of heavy metals associated with phosphate was evaluated in a column test of sediment with overlying water at a volume ratio of 1: 1 for 131 days. Sulfide was significantly oxidized by calcium nitrate, as its amount was reduced substantially by $85 \%$ from the 20 th to the 30 th day, with a decrease in the oxidation-reduction potential to $-68 \mathrm{mV}$ and a simultaneous increase in $\mathrm{pH}$ to 9.83 . Over $50 \%$ of the mobile $\mathrm{Zn}, \mathrm{Pb}$ and $\mathrm{Cu}$ were reprecipitated in the sediment when the phosphate was partially released. It is proposed that the heavy metal immobilization was related to the phosphate content in the pore water due to the precipitation of heavy metals and phosphorus on the surface of Fe hydroxide particles after oxidation. This is supported by chemical
\end{abstract}


fraction analysis of the heavy metals in the sediment, which indicated increased residual fractions of heavy metals. Our results provide an insight into the remediation of sediment by oxidation with a self-stabilization of heavy metals and phosphate.

\section{Practitioner points}

Effective removal of sulfide after calcium nitrate injection was achieved Metal immobilization was related to the phosphate content in pore water

Over $50 \%$ of mobile $\mathrm{Zn}, \mathrm{Pb}$ and $\mathrm{Cu}$ might be reprecipitated in sediment

Oxidizable fraction of heavy metal predominantly transformed to its residual fraction

\section{Keywords}

Heavy metal; Nitrate calcium; Iron oxyhydroxide; Phosphorus; Redox immobilization; Sediment

\section{Introduction}

Black-odorous water bodies, such as highly eutrophic small creeks near industrial zones, have attracted much attention by environmental researchers and governors. The anaerobic sediment in creeks releasing high concentrations of sulfur and ammonia is predominantly responsible for the black-odorous water (He et al., 2017; Yin, Yang, \& Kong, 2019). Various technologies have been applied to the solution of the odor problem in creek (Liu, Zhang, Mao, \& Yan, 2016). Among these technologies, the injection of calcium nitrate has been identified as an in situ treatment approach to rapidly improve the water quality of creeks since it was introduced by Ripl in 1976 (Ripl, 1976; Wang, Wang, \& Zhang, 2018). In the remediation processing, the calcium nitrate $\left(5.2-256 \mathrm{~g} \mathrm{~N} / \mathrm{m}^{2}\right)$ dosed in the system took part in oxidation reactions with pollutants such as organic matter, sulfide, and ammonia in the anaerobic sediment (He et al., 2017; Lin et al., 2015; Liu et al., 2017; McGuire et al., 2002). Meanwhile, the change of chemical properties within the sediment results in the release of heavy metals ( $\mathrm{Li}$, Arocena, Zhang, Thring, \& Li, 2017). Similar phenomena were found in the mobility of phosphate in the sediments in eutrophic waters, which described the phosphate releasing in the remediation process (Ma, Zhu, Yang, \& Li, 2017). Therefore, the mobility of heavy metals and phosphorus is an important issue in the remediation of sediments when considering the application of calcium nitrate (Wu, Qi, \& Xia, 2017).

As known, the migration of heavy metal in contaminated sediment is relative to its species (Ali \& Khan, 2018; Guan et al., 2016). Different factors such as the oxidation-reduction potential (ORP), sulfur and pH affect the transfer and biogeochemical cycling of heavy metals in the environment (Ali \&Khan, 2019; Ali, Khan, \& Ilahi, 2019; Li et al,. 2017). A low ORP makes iron oxides unstable and reduces the binding of 
associated heavy metals, increasing the possibility of sediment-water transfer as the ORP is reduced (Liu et al., 2017). With low ORP values (Eh), however, the binding of cadmium (Cd) and zinc ( $\mathrm{Zn}$ ) was enhanced in the presence of carbonate (Guo, Delaune, \& Patrick, 1997) and the binding capacity of As, $\mathrm{Cd}, \mathrm{Cr}$ and $\mathrm{Zn}$ was also enhanced by sulfide and organic matter. Chen et al. (2007) showed that heavy metals coprecipitated with calcium as double hydroxides such as $\left(\mathrm{Ca}_{2} \mathrm{Cr}(\mathrm{OH})_{7} \cdot 3 \mathrm{H}_{2} \mathrm{O}, \quad \mathrm{Ca}_{2}(\mathrm{OH})_{4} 4 \mathrm{Cu}(\mathrm{OH})_{2} \cdot 2 \mathrm{H}_{2} \mathrm{O}\right.$ and $\left.\mathrm{CaZn}_{2}(\mathrm{OH})_{6} \cdot 2 \mathrm{H}_{2} \mathrm{O}\right)$ which was immobile. In fact, sulfur in sediment is high sensitive to the calcium nitrate. When it is oxidized and removed, sulfur-associated heavy metals would possible release into the overlying water (Jonge, Teuchies, Meire, Blust, \& Bervoest, 2012). The percentage of heavy metals associated with reducible fraction and oxidizable fraction was decreased with the treatment of calcium nitrate (Ou, Sun, $\& \mathrm{Xu}, 2013)$. Therefore, the species changing of heavy metals should be investigated with the soil physicalchemical properties, which may lead to their migration from sediment to water. Moreover, the mobilization of phosphorus was affected by many factors, including Eh, pH, microbial activity and hydrodynamics (Bai, Deng, Cui, \& Ouyang, 2007; Kang, Peng, Tian, \& Zhang, 2018; Liu et al., 2012; Wang et al., 2013). Boström, Persson, and Broberg (1988) found that the high $\mathrm{pH}$ would weaken the P-binding capacity of $\mathrm{Al}$ and $\mathrm{Fe}$ compounds. Phosphorus release was inhibited by calcium nitrate through changing its status in the sediment. Two possible routes were proposed (Ruban \& Demare, 1998; Yamada et al., 2012): (1) Fe(II) is oxidized to amorphous $\mathrm{Fe}(\mathrm{OOH})$ after the injection of calcium nitrate, which has larger surface adsorption sites and a stronger adsorption force with phosphorus than Fe(II); and (2) the releasing metal ions form less soluble apatite minerals with dissolved phosphate in the interstitial water. Accordingly, it is proposed that the migration of heavy metals in the remediation of sediment via calcium nitrate has effect on the phosphate releasing. However, the interaction between phosphorus and heavy metals after adding calcium nitrate has not been introduced in available literature. Thus, a synergistic effect of heavy metals and phosphate needs to be taken into account.

The purpose of this investigation was to estimate the impact of remediation on the potential release of heavy metal associated with phosphate after injecting calcium nitrate. Changes in the sulfur and iron contents, the $\mathrm{Eh}$ and the $\mathrm{pH}$ in the sediment were measured. A further investigation on the coordinated behavior between the phosphorus and heavy metals was conducted. The results provide insight into the oxidation strategy for sediment remediation and the governance of heavy metal pollution and eutrophication in water.

\section{Materials and methods}

\subsection{Sampling and pretreatment}


The sediment and overlying water samples were collected from Puhuitang Creek, Shanghai, China. This creek is a branch of the Caohejing River, which cross the Central Business District (CBD) of the city. The geographical coordinates are $31^{\circ} 10^{\prime} 34.7^{\prime \prime} \mathrm{N}, 121^{\circ} 25^{\prime} 34.4^{\prime \prime} \mathrm{E}$. This area is in andustrial park with over 20 manufactories. The creek was heavily contaminated by the discharge of wastewater from industry plants nearby. There was a large amount of heavy metals in the sediment. The anaerobic degradation of organic matter in the sediments led to black water and the emission of odor. The overlying water was filtered by a $0.45 \mu \mathrm{m}$ membrane. The interstitial water was obtained by the centrifugation of wet sediment at $5000 \mathrm{rpm}$ for 20 min (HAREAUS, Primo, Germany). The laboratory sediments were collected from the surface of the bottom creek, with a depth of $10 \mathrm{~cm}$. The sediment was dried at room temperature. Then, plant roots, benthic organisms and other large objects impurities were removed from the dry samples. The samples were sieved with a standard 100 mesh. All solid samples were stored at $-4{ }^{\circ} \mathrm{C}$ prior to further processing and analysis. The typical concentrations of heavy metals, phosphorus and acid volatile sulfide (AVS) and the $\mathrm{pH}$ and Eh values are shown in Table 1, which was close to the average levels of branch creeks in Shanghai (Deng, Zhang, Wang, Chen, \& Xu, 2010; Yang, Chen, Liu, Shi, \& Meng, 2014; Zhang, Deng, Wang, Chen, \& Xu, 2013).

\subsection{Experimental procedures}

The static method for the simulation study of the stabilization of phosphate and heavy metals in calcium nitrate sediment was used to investigate the behavior of pollutants during the remediation process. The simulated experiment used a cylindrical reaction device with a height of $80 \mathrm{~cm}$ and a diameter of $20 \mathrm{~cm}$. The sediment and the overlying water were placed in a cylindrical hard plastic container at a volume ratio of 1: 1 for culture. In addition, the depth of the sediment and the overlying water was $30 \mathrm{~cm}$. The container was left open at the top to keep the water in contact with air to simulate natural environmental exchange. To remove the impact of the background in the sediment, a control sample without the addition of calcium nitrate was tested.

Calcium nitrate $\left(149 \mathrm{~g} \mathrm{~N} \cdot \mathrm{m}^{2}\right)$ was added by liquid injection. Considering the infiltration of $\mathrm{NO}_{3}$ in the sediment, the injection site was located $5 \mathrm{~cm}$ below the sediment and water interface, ensuring an effective depth of $10 \mathrm{~cm}$. To achieve the complete oxidation of total sulfides, the injection was repeated two times on the 1st day and the 26th day during the 131 days of the experiment, with an interval of 25 days between each injection.

All experiments were performed in triplicate. The data are presented as the average values with the standard deviation.

\subsection{Chemical analysis of heavy metals}




\subsubsection{Total metals concentration analysis}

The total metals solution of sediments was acquired by digesting $0.1 \mathrm{~g}$ of sediment samples with $2.5 \mathrm{~m} 1$ of a $72 \% \quad \mathrm{HClO}_{4}$ solution, $5 \mathrm{ml}$ of a $65 \% \quad \mathrm{HNO}_{3}$ solution and $2.5 \mathrm{ml}$ of a $40 \% \mathrm{HF}$ solution in digestion furnace(SH220N, Haineng, China). Inductively coupled plasma atomic emission spectroscopy (ICP-AES) was used to detect the heavy metals concentration in the solution and to analyze the heavy metals in the speciation extraction.

\subsubsection{Chemical fraction analysis of heavy metals}

The Community Bureau of Reference (BCR) extraction method for metal fractionation is a widely used analysis method. The extractions were carried out by following the method applied in our previous work on creek sediments. After each step of extraction, the sample was washed twice with $10 \mathrm{~mL}$ of distilled water (shaking for $15 \mathrm{~min}$, at $25^{\circ} \mathrm{C}$ ) and centrifuged for $30 \mathrm{~min}$ each time. The centrifuge wash was combined with liquid extraction. The association of heavy metals with each chemical fraction was denoted as F1 acid extractable, F2 reducible, F3 oxidizable, and F4 residual. The following steps list the specific speciation extraction in detail (Guevara-Riba, Sahuquillo, Rubio, \& Rauret, 2004):

Step 1 (F1) (acid extractable fraction): Approximately $1 \mathrm{~g}$ of dry sediment was placed into $100 \mathrm{~mL}$ polypropylene centrifuge tube. Then, $40 \mathrm{~mL}$ of $0.11 \mathrm{~mol} \mathrm{~L}^{-1}$ acetic acid was added to the tube, followed by shaking in an orbital mechanical shaker for $16 \mathrm{~h}$ at a room temperature of $25{ }^{\circ} \mathrm{C}$.

Step 2 (F2) (iron and manganese-reducible fraction): Approximately $40 \mathrm{~mL}$ of $0.1 \mathrm{~mol} \mathrm{~L}^{-1}$ hydroxylamine (with a $\mathrm{pH}$ adjusted to 2 by the addition of $0.1 \mathrm{~mol} \mathrm{~L}^{-1} \mathrm{HCl}$ ) was added to the residue from Step 1 in the centrifuge tube.

Step 3 (F3) (oxidizable fraction): Approximately $10 \mathrm{~mL}$ of $30 \% \mathrm{~W} \mathrm{~V} \mathrm{~V}^{-1} \mathrm{H}_{2} \mathrm{O}_{2}$ was added into the residue from Step 2 in the centrifuge tube. The tube was digested at room temperature for $1 \mathrm{~h}$. Another $10 \mathrm{~mL}$ of $30 \% \mathrm{~W} \mathrm{~V}^{-1} \mathrm{H}_{2} \mathrm{O}_{2}$ was added. Again, the covered tube was heated to $85{ }^{\circ} \mathrm{C}$ and digested for $1 \mathrm{~h}$. After cooling, 50 $\mathrm{mL}$ of $1.0 \mathrm{~mol} \mathrm{~L}-1$ ammonium acetate (with a $\mathrm{pH}$ adjusted to 2 by the addition of concentrated $\mathrm{HNO}_{3}$ ) was added to the residue and the tube was shaken for $16 \mathrm{~h}$ at room temperature.

Step 4 (F4) (residual fraction): The residue from Step 3 was digested using a 3:1 mixture of $\mathrm{HNO}_{3}-\mathrm{HF}$.

For quality control of the extraction data, the amount of heavy metals in each step was summed together and compared to separate the single total metal analysis for each sample. The sum of the fractions was within $10 \%$ of the independent total. The discussion on the metal partitioning between fractions was presented in terms of the $\%$ of the sample total. 


\subsection{AVS and simultaneous extract metal measurement}

Analyses of the AVS and simultaneous extract metal (SEM) concentrations ( $\mathrm{mg} \mathrm{kg}^{-1}$ ) in sediments largely followed the method recommended by United States Environmental Protection Agency (USEPA) (Yang et al., 2014). Typically, $2.0 \mathrm{~g}$ of fresh sediment was added into the flask. Then, a round-bottom flask was filled with $\mathrm{N}_{2}$ for $10 \mathrm{~min}$, and the AVS receiving bottle was prepared. A total of $40 \mathrm{~mL}$ of $0.5 \mathrm{~mol} \mathrm{~L}^{-1} \mathrm{NaOH}$ was added to the receiving flask as an AVS receiver. The $\mathrm{N}_{2}$ flow rate was reduced, and the aeration was continued for $10 \mathrm{~min}$. Then $20 \mathrm{~mL}$ of $6 \mathrm{~mol} / \mathrm{L} \mathrm{HCl}$ was added into the flask to form $\mathrm{H}_{2} \mathrm{~S}$ with the sediment. $\mathrm{N}_{2}$ was continuously added at a flow rate of $20 \mathrm{~cm}^{3} \mathrm{~min}^{-1}$, and digestion was carried out for $1 \mathrm{~h}$. In this process, $\mathrm{N}_{2}$ was used as a purge gas to carry $\mathrm{H}_{2} \mathrm{~S}$ gas into the $\mathrm{N}, \mathrm{N}$-dimethylphenyl-p-diamine (DMPD) solution in the presence of ferric chloride $(\mathrm{FeCl} 3)$. The AVS extraction process was conducted for $45 \mathrm{~min}$, with stirring at room temperature to ensure complete $\mathrm{H} 2 \mathrm{~S}$ absorption. The H2S concentration in the DMPD solution was quantified using a UV1000 spectrophotometer. The concentrations of $\mathrm{Cu}, \mathrm{Pb}$ and $\mathrm{Zn}$ during the AVS extraction were operationally defined as the SEM and measured by ICP-AES analysis after filtering with a $0.45 \mu \mathrm{m}$ acetate membrane.

All sample analyses were performed in triplicate. The recovery rates were between $90 \%$ and $110 \%$, and the average values are reported.

\subsection{Phosphate determination}

The total phosphate (TP) in the sediment was extracted by following the Standards, Measurements and Testing (SMT) Program of the European Commission (Medeiros, Cid, \& Gómez, 2005). The SMT protocol consists of three extraction procedures that were applied to $0.2 \mathrm{~g}$ aliquots of sediment samples:

1. The TP was measured by calcination in a muffle furnace $\left(450{ }^{\circ} \mathrm{C}\right)$ for $3 \mathrm{~h}$ and then extraction $(16 \mathrm{~h})$ using a solution of $20 \mathrm{~mL}$ of $3.5 \mathrm{~mol} \mathrm{~L}^{-1} \mathrm{HCl}$,

2. Inorganic phosphorus (IP) was determined by an extraction $(16 \mathrm{~h})$ with $20 \mathrm{~mL}$ of $1 \mathrm{~mol} \mathrm{~L}^{-1} \mathrm{HCl}$. The residue of this extraction was placed in a porcelain crucible and calcined in a furnace for $3 \mathrm{~h}$ at $450{ }^{\circ} \mathrm{C}$. Then, the residue was extracted again $(16 \mathrm{~h})$ with $20 \mathrm{~mL}$ of $1 \mathrm{~mol} \mathrm{~L}^{-1} \mathrm{HCl}$. After centrifugation, the organic phosphorus $(\mathrm{OP})$ in the extract was determined.

3. An extraction (16 h) using $20 \mathrm{~mL}$ of $1 \mathrm{~mol} \mathrm{~L}^{-1} \mathrm{NaOH}$ was performed, and after centrifugation and separation of the supernatant liquid, the residue was extracted again with $20 \mathrm{~mL}$ of $1 \mathrm{~mol} \mathrm{~L}^{-1} \mathrm{HCl}(16 \mathrm{~h})$. Apatite phosphorus (AP) was determined in the extract. Approximately $4 \mathrm{~mL}$ of $3.5 \mathrm{~mol} \mathrm{~L}^{-1} \mathrm{HCl}$ was added to one aliquot of $10 \mathrm{~mL}$ of the $1 \mathrm{~mol} \mathrm{~L}^{-1} \mathrm{NaOH}$ extract and allowed to stand for $16 \mathrm{~h}$ to precipitate organic matter. The non-apatite inorganic phosphorus (NAIP) in the supernatant liquid was determined. 
The concentration of aqueous phosphate was determined by the spectrophotometric method.

\subsection{Statistical analysis}

All the analyses were performed in the $\mathrm{R}$ environment (version 3.4.4). One-way analysis of variance (ANOVA) was conducted to assess the concentration differences of TP before and after the treatments with a significant level of $p=0.05$.

\section{Results and discussion}

\subsection{The effect of calcium nitrate on heavy metals and SEM/AVS in sediments}

\subsubsection{Transformation of heavy metals in sediments}

The variations in the concentrations of heavy metals ( $\mathrm{mg} \mathrm{kg}^{-1}$ dry weight) after dosing calcium nitrate within 120 days are shown in Figure 1. The amounts of heavy metals were in the following order: $\mathrm{Cu}>\mathrm{Pb}>\mathrm{Zn}$, with a mean value of $\mathrm{Cu} 623 \mathrm{mg} \mathrm{kg}^{-1}, \mathrm{Zn} 169 \mathrm{mg} \mathrm{kg}^{-1}$ and $\mathrm{Pb} 248 \mathrm{mg} \mathrm{kg}^{-1}$ (Figure 1).

Although there were no significant changes in the concentrations of heavy metals, the chemical partitioning of heavy metals was altered over time (Figure 2). The results of ANOVA for the differences of four chemical speciations are provided in Table S1, Table S2 and Table S3. The chemical speciation of Cu was mainly in its oxidizable fraction (F3) and residual fraction (F4) in the original sediment, accounting for 53\% and $46 \%$ of the total, respectively (Figure 2). In comparison, the amounts of $\mathrm{Cu}$ in the iron and manganesereducible fraction $(\mathrm{F} 2)$ and the acid extractable fraction $(\mathrm{F} 1)$ were very low. After adding calcium nitrate, the amount of $\mathrm{F} 3-\mathrm{Cu}$ gradually decreased to $30 \%$ of the total amount of $\mathrm{Cu}$, with the increasing of $\mathrm{F} 1-\mathrm{Cu}$ to $8 \%$ and F4-Cu to $61 \%$ in 120 days. A similar trend was observed in the case of $\mathrm{Pb}$ and $\mathrm{Zn}$ (Figure 2). In 120 days, the proportion of F4-Zn increased from $44 \%$ to $51 \%$ and that of F1-Zn increased from $36 \%$ to $41 \%$, with the reduction of $\mathrm{F} 3-\mathrm{Zn}$ from $15 \%$ to $4 \%$. For $\mathrm{Pb}$, the $\mathrm{F} 3-\mathrm{Pb}$ decreased from $30 \%$ to $5 \%$, resulting in increases in $\mathrm{F} 4-$ $\mathrm{Pb}$ to $81 \%$ and $\mathrm{F} 1-\mathrm{Pbo} 16 \%$. This observation implied that the F3 fraction of heavy metals predominantly transformed to its F4 fraction. It is interesting that the F3 fraction decreased in the first 20 days with the simultaneous increase in F4. On the contrary, the increase in F1 happened after 40 days in the remediation. Compared to the relatively stable species of heavy metals in the control sediment (Table S4), the changing of the heavy metal speciation after injecting meant that the heavy metals were stabilized in the initial period with $\mathrm{Ca}\left(\mathrm{NO}_{3}\right)_{2}$.

The amount of heavy metals had no significant migration from the sediment to the overlying water during the remediation period of calcium nitrate. Similar results were found in the related research (Shao, Zhang, \& Fang, 2009). However, the speciation of heavy metals was changed. Shao et al. (2009) reported that heavy 
metals $\mathrm{Cu}, \mathrm{Pb}$ and $\mathrm{Zn}$ existed mainly in the oxidizable fraction (F3) while the $\mathrm{F} 3$ of heavy metal sharply decreased as remediation process. The F3 fraction reduction was contributed to the oxidation of sulfide affinity to heavy metals. This supposed the releasing of partial heavy metals. In comparison, the F4 fraction of three heavy metals was increased after remediation in current work. This observation suggests that heavy metals in sediment have the tendency to transform to the residue fraction $(\mathrm{F} 4)$, which is probably relative to anions in sediment such as phosphate.

\subsubsection{The change of AVS and SEM/AVS in sediments}

The variations of AVS and SEM/AVS after the injection of $\mathrm{Ca}\left(\mathrm{NO}_{3}\right)_{2}$ are shown in Table 2. The AVS in the sediment decreased rapidly from the initial $6376 \mathrm{mg} \mathrm{kg}^{-1}$ to $942 \mathrm{mg} \mathrm{kg}^{-1}$ in 26 days at a rate of $209 \mathrm{mg} \mathrm{kg}^{-1} \mathrm{~d}^{-}$ ' after the addition of calcium nitrate. Then, the AVS decreased gradually to $238.4 \mathrm{mg} \mathrm{kg}$ ' on the 131 st day, showing that $85 \%$ of the AVS was removed. It appeared that the AVS consumed a large amount of calcium nitrate when converted to $\mathrm{SO}_{4}^{2}$, suggesting that $\mathrm{S}$ might form heavy metal sulfides in the sediment. The decrease in the F3 fraction of heavy metals was assigned to the reduction of heavy metal sulfides in the reaction with calcium nitrate. In contrast, the increase in SEM/AVS was recorded after 26 days of remediation and reached the highest value of 7.5 on the 131st day (Figure S1), which was consistent with the decrease in the F3 fraction of heavy metals. The F3 fraction in the BCR analysis refers to the heavy metals bound to the sulfide and organic matter. Hence, the reduction in the F3 fraction suggested the simultaneous diminishment of organic matter and sulfide (Figure S2). Generally, the mobilization of heavy metals often occurs when SEM/AVS is more than 1.0, and this leads to an increase in the F1 fraction of heavy metals (McQueen et al., 2016). However, in the current case, the increases of $\mathrm{Cu}, \mathrm{Zn}$ and $\mathrm{Pb}$ in the $\mathrm{F} 1$ portion were $10 \%, 5 \%$ and $12 \%$ respectively, which were not as much as expected. The $\mathrm{BCR}$ results showed that the increases of $\mathrm{Cu}, \mathrm{Zn}$ and $\mathrm{Pb}$ in the $\mathrm{F} 4$ fraction were $14 \%, 7 \%$ and $12 \%$, respectively (Figure 2). Thus, the major path of transformation of the heavy metals was changed to the F4 fraction. For instance, the oxidation state changes of $\mathrm{Zn}$ and $\mathrm{Pb}$ showed a large drop at the beginning of the test; for example, the decreases of $\mathrm{Cu}, \mathrm{Zn}$ and $\mathrm{Pb}$ in the $\mathrm{F} 3$ fraction were $17 \%, 11 \%$ and $25 \%$, respectively (Figure 2).M" shape variation after injection in the first 60 days, with a maximum of 9.83. After 60 days, the $\mathrm{pH}$ dropped and remained at 8.35. The huge variation in $\mathrm{pH}$ was attributed to both the strong alkalinity of calcium nitrate and the buffering capacity of the sediments, along with the occurrence of chemical reactions.

So far, it has been shown that the AVS concentration decreased as the $\mathrm{pH}$ increased and the Eh decreased (Figure S5). According to the redox reaction with $\mathrm{NO}_{3}$ as an electron acceptor, the following oxidation of sulfides to sulfate could be expressed as follows:

$10 \mathrm{FeS}+18 \mathrm{NO}_{3}^{-}+46 \mathrm{H}_{2} \mathrm{O} \rightarrow 10 \mathrm{FeOOH}+10 \mathrm{SO}_{4}^{2-}+82 \mathrm{H}^{+}+9 \mathrm{~N}_{2}(1)$ 
The generation of $\mathrm{SO}_{4}{ }^{2}$ was accompanied by a decrease in $\mathrm{H}^{+}$, leading to an increase in the $\mathrm{pH}$ of the sediment. This is responsible for the observation that the final pHof 8.35 after 131 days of reaction was still higher than the raw $\mathrm{pH}$ of 7.5 (Figure 4).

\subsection{Effect of substrate alteration on $P$ and heavy metals}

\subsubsection{The change in Fe and $S$ in the sediment}

Because the conversion between $\mathrm{Fe}(\mathrm{III})$ and $\mathrm{Fe}(\mathrm{II})$ depended largely on the level of the ORP, the value of $\mathrm{Fe}(\mathrm{III}) / \mathrm{Fe}$ (II) was used to determine the ORP in the sediment (Nguyen et al., 2018). In the absence of calcium nitrate, the fluctuations of $\mathrm{Fe}(\mathrm{III}) / \mathrm{Fe}$ (II) were relatively stable $(0.034 \sim 0.076)$ in the sediment (Figure 4). Compared to the control, $\mathrm{Fe}(\mathrm{III}) / \mathrm{Fe}(\mathrm{II})$ significantly increased after the addition of calcium nitrate in the initial 54 days, to the highest value of 0.131 on the 26th and 54th days. Then, it decreased gradually to 0.028 at a rate of $0.0013 \mathrm{~d}^{-1}$ at the end of experiment (Figure 4). Fe(II) was easily converted to $\mathrm{Fe}(\mathrm{III})$ by the oxidation of calcium nitrate ( $\mathrm{Li}$ et al., 2018), but the variation range of $\mathrm{Fe}(\mathrm{III}) / \mathrm{Fe}(\mathrm{II})$ was still less than 1 (0.028 0.131). This was probably due to the strong anaerobic environment. Therefore, the oxidation of calcium nitrate was related to the specific speciation of Fe in the sediment.

$\mathrm{Fe}$ and $\mathrm{S}$ were changed along with the Eh and the $\mathrm{pH}$. When most Fe and $\mathrm{S}$ existed as $\mathrm{FeS}$ in the sediment, $\mathrm{S}^{2}$ was converted to $\mathrm{SO}_{4}{ }^{2}$ and released into water, and $\mathrm{Fe}(\mathrm{II})$ was released at the same time (Baldwin \& Mitchell, 2012). In the presence of nitrate, the following reaction occurred (Na, Wang, \& Park, 2006):

$$
10 \mathrm{FeS}+18 \mathrm{NO}_{3}^{-}+46 \mathrm{H}_{2} \mathrm{O} \rightarrow 10 \mathrm{FeOOH}+10 \mathrm{SO}_{4}^{2-}+82 \mathrm{H}^{+}+9 \mathrm{~N}_{2} \text { (2) }
$$

The value of $\mathrm{Fe}(\mathrm{III}) / \mathrm{Fe}(\mathrm{II})$ was in a stable range of fluctuations and was poorly correlated with the reduction of AVS after the addition of calcium nitrate (Figure S6). Therefore, the oxidation of Fe by calcium nitrate did not significantly affect the speciation of $\mathrm{FeS}$ in the sediment. The increase of $\mathrm{Fe}(\mathrm{III}) / \mathrm{Fe}(\mathrm{II})$ was restricted when the Fe mainly existed as FeS in the sediment, which indicated that calcium nitrate had no obvious effect on $\mathrm{Fe}(\mathrm{III}) / \mathrm{Fe}(\mathrm{II})$.

\subsubsection{Effects of Fe and S on phosphorus}

Previous research has shown a correlation between iron, sulfur and phosphorus in sediment (Kraal et al., 2015). Phosphorus was not only bound to $\mathrm{Fe}(\mathrm{OOH})$ but also adsorbed on FeS (Martins, Peixoto, Brito, \& Nogueira, 2014). Accordingly, the release of phosphorus was suggested after Fe(II) and sulfide oxidation. Figure 5 shows the relationship between $\mathrm{Fe}, \mathrm{S}$ and the release of phosphorus after the addition of calcium nitrate. The correlation coefficients of AVS and $\mathrm{Fe}(\mathrm{III}) / \mathrm{Fe}(\mathrm{II})$ were 0.494 and 0.077 , respectively. The change of $\mathrm{Fe}(\mathrm{III}) / \mathrm{Fe}$ (II) had no obvious effect on the concentration of phosphorus in the interstitial water, while the impact of AVS was quite significant. The relationship between the AVS and the aqueous phosphorus 
suggested that the reduction of sulfide was related to the decrease in aqueous phosphorus and implied the precipitation of $\mathrm{P}$ after the oxidation of sulfide, which was probably responsible for the increase in the residual fraction of heavy metals.

\subsection{Synergistic stability of phosphorus and heavy metals}

To estimate the mobility of heavy metal and phosphorus, their concentrations in interstitial water were detected. As the residue fraction of heavy metal increased (Figure 2), the change of aqueous heavy metal could be described as the following:

$10 \mathrm{FeS}+18 \mathrm{NO}_{3}^{-}+46 \mathrm{H}_{2} \mathrm{O} \rightarrow 10 \mathrm{FeOOH}+10 \mathrm{SO}_{4}^{2-}+82 \mathrm{H}^{+}+9 \mathrm{~N}_{2}$

where $\mathrm{C}_{\text {aq(i) }}$ and $\mathrm{C}_{\text {aq(o) }}$ are the concentrations of aqueous heavy metal in interstitial water with and without the injection of calcium nitrate after $t$ days, respectively. The percentage of aqueous metals indicated the amount of heavy metal release compared to that in the control experiment. It was assumed that when the aqueous heavy metal content was lower, more heavy metals were precipitated.

Heavy metals precipitate under alkaline conditions to form hydroxide (acid extractable fraction), which is unstable. As shown in Figure 6, the metal residue for $\mathrm{Cu}, \mathrm{Zn}$ and $\mathrm{Pb}$ increased as the concentration of $\mathrm{TP}$ in the interstitial water decreased. The stability of heavy metal is related to phosphorus by forming heavy metal phosphate (residual fraction). The linear correlation obtained between the three heavy metals $(\mathrm{Cu}, \mathrm{Zn}$ and $\mathrm{Pb})$ and TP were as follows (igure 6):

$$
\begin{gathered}
\mathrm{Cu}(\%)=-0.6297 \mathrm{TP}+64.45, \mathrm{r}=-0.820 \\
\mathrm{Zn}(\%)=-1.079 \mathrm{TP}+64.7, \mathrm{r}=-0.948 \\
\mathrm{~Pb}(\%)=-0.4200 \mathrm{TP}+85.51, \mathrm{r}=-0.611
\end{gathered}
$$

The stronger correlation between the heavy metals and the TP concentration in the interstitial water illustrated the binding of heavy metals and phosphorus (Figure 6). As the correlation coefficient was lower than -0.8 , a good correlation between $\mathrm{Zn}$ and $\mathrm{P}$ was indicated, while that of $\mathrm{Pb}$ was poor (Figure 6). Therefore, different heavy metals were combined with phosphorus in different forms, which led to differences in their coprecipitation effects.

It was reported that for each common heavy metal, the $K_{\text {sp }}$ values of phosphate metals are slightly higher than those of sulfide metals (Banfalvi, 2006). For example, $\mathrm{Pb}_{5}\left(\mathrm{PO}_{4}\right)_{3} \mathrm{OH}$ reached 62.80 and the phosphates of $\mathrm{Cu}$ and $\mathrm{Zn}$ reached 53.96 and 49.10, respectively. The $\mathrm{K}_{\text {sp }}$ values were higher than the corresponding $\mathrm{K}_{\mathrm{sp}}$ values for the sulfides; the $\mathrm{K}_{\mathrm{sp}}$ values of $\mathrm{CuS}, \mathrm{PbS}$ and $\mathrm{ZnS}$ were 44, 28 and 23, respectively. These results illustrate that the combination of phosphorus and heavy metals most likely produced heavy metal phosphates in sediments, which promoted the stabilization of heavy metals and phosphorus at the same 
time. At a pH of 8.5, $\mathrm{HPO}_{4}^{2-}$ was the predominant species of phosphorus (Liu, Sheng, Dong, \& Ma, 2012), which consequently suggested that the effect of Ca-P precipitation on the decrease of TP in the interstitial water was poor with the high solubility of $\mathrm{CaHPO}_{4}($ Figure S7). Accordingly, the adsorption of heavy metals with the formation of Ca-P precipitates was not the predominant reason for the increase in the residual fractions of heavy metals. Therefore, it was highly likely that the phosphorus and heavy metals produced heavy metal phosphates in the sediment, which simultaneously stabilized the heavy metals and the phosphorus.

\section{Conclusions}

The injection of calcium nitrate was used in the remediation of sediment in a simulated column experiment. The heavy metal and phosphorus contents both in sediment and interstitial water were recorded. Under the action of calcium nitrate, sulfide was significantly oxidized by calcium nitrate as its amount was reduced substantially by $85 \%$ from the 20 th to the 30 th day with a linear change of the ORP-pH profiles. Simultaneously, the amount of heavy metals associated with both the acid soluble fraction and the residue fraction increased. Over $50 \%$ of the mobile $\mathrm{Zn}, \mathrm{Pb}$ and $\mathrm{Cu}$ was reprecipitated, which seemed to be relative to the loss of phosphorus from interstitial water and contributed to the formation of heavy metal phosphates given the low $\mathrm{K}_{\mathrm{sp}}$ value. This synergistic relationship of phosphorus and heavy metal in interstitial water occurred significantly in the case of $\mathrm{Zn}$ and $\mathrm{Pb}$ immobilization.

In practical strategies for sediment remediation, heavy metal contamination is often considered. Although calcium nitrate is recommended by the USEPA to reduce organic matter via the oxidation status of the sediment, the changing of sulfide species by calcium nitrate led to the mobilization of heavy metals to the water body from the sediment. To solve the issue, our results provide a promising approach for the remediation of sediment with the simultaneous use of a phosphate agent to stabilize heavy metals in the form of insoluble phosphate. This extends the application of $\mathrm{Ca}\left(\mathrm{NO}_{3}\right)_{2}$ in both sediment and soil remediations and avoids secondary contamination.

\section{Acknowledgments}

This study was supported by the National Natural Science Foundation Project of China (No. 51678351) and the Project of Environmental Protection Research of Shanghai (201407 and 201203). We also appreciate the Instrumental Analysis \& Research Center of Shanghai University for help with the sample characterizations. The authors declare that they have no conflicts of interest in this work.

\section{Data value statement}


The data used to support the findings of this study are available from the corresponding author upon request.

\section{References}

Ali, H., \& Khan, E. (2018). What are heavy metals? long-standing controversy over the scientific use of the term 'heavy metals' - proposal of a comprehensive definition. Toxicological \& Environmental Chemistry, 100, 6-19. doi:10.1080/02772248.2017.1413652

Ali, H., \& Khan, E. (2019). Trophic transfer, bioaccumulation, and biomagnification of non-essential hazardous heavy metals and metalloids in food chains/webs - concepts and implications for wildlife and human health. Human and Ecological Risk Assessment: An International Journal, 25, 13531376. doi:10.1080/10807039.2018.1469398

Ali, H., Khan, E., \& Ilahi, I. (2019). Environmental chemistry and ecotoxicology of hazardous heavy metals: Environmental persistence, toxicity, and bioaccumulation. Journal of Chemistry. doi:10.1155/2019/6730305

Bai, J., Deng, W., Cui, B., \& Ouyang, H. (2007). Water diffusion coefficients of horizontal soil columns from natural saline-alkaline wetlands in a semiarid area. Eurasian Soil Science, 20, 660664. doi: 10.1134/S1064229307060075

Baldwin, D. S., \& Mitchell, A. (2012). Impact of sulfate pollution on anaerobic biogeochemical cycles in a wetland sediment. Water research, 46, 965-974. doi:10.1016/j.watres.2011.11.065

Banfalvi, G. (2006). Removal of insoluble heavy metal sulfides from water. Chemosphere, 63, 12311234. doi:10.1016/j.chemosphere.2005.08.066

Boström, B., Persson, G., \& Broberg, B. (1988). Bioavailability of different phosphorus forms in freshwater systems. Hydrobiologia, 170, 133-155. doi: 10.1007/BF00024902

Chen, Q. Y., Hills, C. D., Tyrer, M., Slipper, I., Shen, H. G., \& Brough, A. (2007). Characterisation of products of tricalcium silicate hydration in the presence of heavy metals. Journal of Hazardous Materials, 147, 817-825. doi: 10.1016/j.jhazmat.2007.01.136

Deng, H. G., Zhang, J., Wang, D. Q., Chen, Z. L., \& Xu, S. Y. (2010). Heavy metal pollution and assessment of the tidal flat sediments near the coastal sewage outfalls of shanghai, china. Environmental Earth Sciences, 60, 57-63. doi: 10.1007/s12665-009-0169-3

Guan, Q., Cai, A., Wang, F., Wang, L., Wu, T., Pan, B., et al. (2016). Heavy metals in the riverbed surface sediment of the Yellow River, China. Environmental Science and Pollution Research, 23, 2476824780. doi:10.1007/s11356-016-7712-Z

Guevara-Riba, A., Sahuquillo, A., Rubio, R., \& Rauret, G. (2004). Assessment of metal mobility in dredged harbour sediments from Barcelona, Spain. Science of the Total Environment, 321, 241255. doi:10.1016/j.scitotenv.2003.08.021

Guo, T., DeLaune, R., \& Patrick, W. (1997). The influence of sediment redox chemistry on chemically active forms of arsenic, cadmium, chromium, and zinc in estuarine sediment. Environment International, 23 , 305-316. doi:10.1016/S0160-4120(97)00033-0

He, Z., Long, X., Li, L., Yu, G., Chong, Y., Xing, W., et al. (2017). Temperature response of sulfide/ferrous oxidation and microbial community in anoxic sediments treated with calcium nitrate addition. Journal of environmental management, 191, 209-218. doi:10.1016/j.jenvman.2017.01.008

Jonge, M. D., Teuchies, J., Meire, P., Blust, R., \& Bervoets, L. (2012). The impact of increased oxygen conditions on metal-contaminated sediments part I: effects on redox status, sediment geochemistry and metal bioavailability. Water Research, 46, 2205-2214. doi:10.1016/j.watres.2012.01.052

Kang, M., Peng, S., Tian, Y., \& Zhang, H. (2018). Effects of dissolved oxygen and nutrient loading on phosphorus fluxes at the sediment-water interface in the hai river estuary, china. Marine Pollution Bulletin, 130, 132-139. doi:10.1016/j.marpolbul.2018.03.029

Kraal, P., Burton, E. D., Rose, A. L., Kocar, B. D., Lockhart, R. S., Grice, K., et al. (2015). Sedimentary ironphosphorus cycling under contrasting redox conditions in a eutrophic estuary. Chemical Geology, 392, 19-31. doi: 10.1016/j.chemgeo.2014.11.006

Li, S., Li, X., \& Li, F. (2018). Fe (II) oxidation and nitrate reduction by a denitrifying bacterium, Pseudomonas stutzeri LS-2, isolated from paddy soil. Journal of Soils and Sediments, 18, 16681678. doi: 10.1007/s11368-017-1883-1

Li, Y., Arocena, J. M., Zhang, Q., Thring, R. W., \& Li, J. (2017). Heavy metals and nutrients (carbon, nitrogen, and phosphorus) in sediments: relationships to land uses, environmental risks, and management. Environmental Science and Pollution Research, 24, 7403-7412. doi: 10.1007/s11356$017-8385-y$ 
Lin, J., Qiu, P., Yan, X., Xiong, X., Jing, L., \& Wu, C.. (2015). Effectiveness and mode of action of calcium nitrate and phoslock? in phosphorus control in contaminated sediment, a microcosm study. Water, Air, \& Soil Pollution, 226, 330. doi: 10.1007/s1127

Liu, P., Bai, J., Ding, Q., Shao, H., Gao, H., \& Xiao, R. (2012). Effects of water level and salinity on tn and tp contents in marsh soils of the yellow river delta, china. CLEAN - Soil Air Water, 40, 11181124. doi: 10.1002/clen.201200029

Liu, T., Zhang, Z., Mao, Y., \& Yan, D. Y. (2016). Induced metal redistribution and bioavailability enhancement in contaminated river sediment during in situ biogeochemical remediation. Environmental Science \& Pollution Research, 23, 6353-6362. doi: 10.1007/s11356-015-5842-3

Liu, X., Tao, Y., Zhou, K., Zhang, Q., Chen, G., \& Zhang, X. (2017). Effect of water quality improvement on the remediation of river sediment due to the addition of calcium nitrate. Science of The Total Environment, 575, 887-894. doi: 10.1016/j.scitotenv.2016.09.149

Liu, Y., Sheng, X., Dong, Y., \& Ma, Y. (2012). Removal of high-concentration phosphate by calcite: effect of sulfate and pH. Desalination, 289, 66-71. doi: 10.1016/j.desal.2012.01.011

Ma, W.-W., Zhu, M.-X., Yang, G.-P., \& Li, T. (2017). In situ, high-resolution DGT measurements of dissolved sulfide, iron and phosphorus in sediments of the East China Sea: Insights into phosphorus mobilization and microbial iron reduction. Marine pollution bulletin, 124, 400410. doi: 10.1016/j.marpolbul.2017.07.056

Martins, G., Peixoto, L., Brito, A. G., \& Nogueira, R. (2014). Phosphorus-iron interaction in sediments: can an electrode minimize phosphorus release from sediments? Reviews in Environmental Science and Bio/Technology, 13, 265-275. doi: 10.1007/s11157-014-9343-5

McGuire, J. T., Long, D. T., Klug, M. J., Haack, S. K., \& Hyndman, D. W. (2002). Evaluating behavior of oxygen, nitrate, and sulfate during recharge and quantifying reduction rates in a contaminated aquifer. Environmental Science \& Technology, 36, 2693-2700. doi: 10.1021/es015615q

McQueen, A. D., Kinley, C. M., Rodgers Jr, J. H., Friesen, V., Bergsveinson, J., \& Haakensen, M. C. (2016). Influence of commercial (Fluka) naphthenic acids on acid volatile sulfide (AVS) production and divalent metal precipitation. Ecotoxicology and environmental safety, 134, 8694. doi: 10.1016/j.ecoenv.2016.08.022

Medeiros, J. G., Cid, B. P., \& Gómez, E. F. (2005). Analytical phosphorus fractionation in sewage sludge and sediment samples. Analytical and Bioanalytical Chemistry, 381, 873-878. doi: 10.1007/s00216-0042989-z

Miao, S., DeLaune, R., \& Jugsujinda, A. (2006). Influence of sediment redox conditions on release/solubility of metals and nutrients in a Louisiana Mississippi River deltaic plain freshwater lake. Science of the Total Environment, 371, 334-343. doi: 10.1016/j.scitotenv.2006.07.027

Na, Y. M., Wang, S., \& Park, S. S. (2006). A mathematical model to estimate nitrate release from ocher pellets applied to anaerobic benthic sediment. Ecological modelling, 199, 324335. doi: 10.1016/j.ecolmodel.2006.05.014

Nguyen, K. A., Borja, D., You, J., Hong, G., Jung, H., \& Kim, H. (2018). Chalcopyrite bioleaching using adapted mesophilic microorganisms: Effects of temperature, pulp density, and initial ferrous concentrations. Materials transactions, 59, 1860-1866. doi: 10.2320/matertrans.M2018247

Ou, F. Z., Sun, G. P., \& Xu, M. Y. Effects of regulatory agent on the heavy metal stability in tidal sediments. Huanjing Kexue, 34, 3888-3893.

Ripl, W. (1976). Biochemical oxidation of polluted lake sediment with nitrate: a new lake restoration method. Ambio, 5, 132-135. doi:10.2307/4312194

Ruban, V., \& Demare, D. (1998). Sediment phosphorus and internal phosphate flux in the hydroelectric reservoir of Bort-les-Orgues, France. Hydrobiologia, 373, 349-359.

Shao, M., Zhang, T., \& Fang, H. H. P. (2009). Autotrophic denitrification and its effect on metal speciation during marine sediment remediation. Water Research, 43, 2961-2968

Sirivedhin, T., \& Gray, K. A. (2006). Factors affecting denitrification rates in experimental wetlands: field and laboratory studies. Ecological Engineering, 26, 167-181. doi: 10.1016/j.ecoleng.2005.09.001

Wang, G.B., Wang, Y., Guo, Y., \& Peng, D.C. (2017). Effects of four different phosphorus-locking materials on sediment and water quality in Xi'an moat. Environmental Science and Pollution Research, 24, 264274. doi: 10.1007/s11356-016-7796-5

Wang, G. B., Wang, Y., \& Zhang, Y. (2018). Combination effect of sponge iron and calcium nitrate on severely eutrophic urban landscape water: an integrated study from laboratory to fields. Environmental Science and Pollution Research, 25, 8350-8363. doi: 10.1007/s11356-017-1161-1

Wang, H., Holden, J., Spera, K., Xu, X. H., Wang, Z. D., Luan, J. H., ... Zhang, Z.J. (2013). Phosphorus fluxes at the sediment-water interface in subtropical wetlands subjected to experimental warming: a microcosm study. Chemosphere, 90, 1794-1804. doi: 10.1016/j.chemosphere.2012.08.044 
Wang, L., Long, X. X., \& Chong, Y. X. (2016) Potential risk assessment of heavy metals in sediments during the denitrification process enhanced by calcium nitrate addition: Effect of AVS residual. Ecological Engineering, 87,333-339. doi: 10.1016/j.ecoleng.2015.12.002

Wu, Q., Qi, J., \& Xia, X. (2017). Long-term variations in sediment heavy metals of a reservoir with changing trophic states: Implications for the impact of climate change. Science of the Total Environment, 609, 242-250. doi: 10.1016/j.scitotenv.2017.04.041

Yamada, T. M., Sueitt, A. P. E., Beraldo, D. A. S., Botta, C. M. R., Fadini, P. S., Nascimento, M. R. L., ... Mozeto, A.A. (2012). Calcium nitrate addition to control the internal load of phosphorus from sediments of a tropical eutrophic reservoir: microcosm experiments. Water Research, 46, 6463--6475. doi: 10.1016/j.watres.2012.09.018

Yang, J., Chen, L., Liu, L. Z., Shi, W. L., \& Meng, X. Z. (2014). Comprehensive risk assessment of heavy metals in lake sediment from public parks in shanghai. Ecotoxicology and Environmental Safety, 102, 129-135. doi: 10.1016/j.ecoenv.2014.01.010

Yang, Y., Zhang, L., Chen, F., Kang, M., Wu, S., \& Liu, J. (2014). Seasonal variation of acid volatile sulfide and simultaneously extracted metals in sediment cores from the Pearl River Estuary. Soil and Sediment Contamination: An International Journal, 23, 480-496. doi: 10.1080/15320383.2014.838207

Yin, H. B., Yang, P., \& Kong, M. (2019). Effects of nitrate dosing on the migration of reduced sulfur in black odorous river sediment and the influencing factors. Chemical Engineering Journal, 371, 516-523. doi: 10.1016/j.cej.2019.04.095

Zhang, J., Deng, H., Wang, D., Chen, Z., \& Xu, S. (2013). Toxic heavy metal contamination and risk assessment of street dust in small towns of shanghai suburban area, china. Environmental Science and Pollution Research International, 20, 323-332. doi: 10.1007/s11356-012-0908-y 
Table 1 Properties of the water and sediment samples from Puhuitang creek

\begin{tabular}{|c|c|c|c|}
\hline & & Overlying water & Sediment \\
\hline \multicolumn{2}{|l|}{$p H$} & 7.83 & 7.25 \\
\hline \multicolumn{2}{|l|}{$E h$} & $22.9 \mathrm{mV}$ & $56 \mathrm{mV}$ \\
\hline \multicolumn{2}{|l|}{$A V S$} & nd & $6376 \mathrm{mg} \mathrm{kg}^{-1}$ \\
\hline \multicolumn{2}{|c|}{ Organic matter } & nd & $107.6 \mathrm{mg} \mathrm{kg}^{-1}$ \\
\hline \multicolumn{2}{|c|}{ Total phosphorus } & $3.188 \mathrm{mg} \mathrm{L}^{-1}$ & $1665 \mathrm{mg} \mathrm{kg}^{-1}$ \\
\hline \multirow{7}{*}{ Heavy metals } & $\mathrm{Cu}$ & nd & $625.4 \mathrm{mg} \mathrm{kg}^{-1}$ \\
\hline & $\mathrm{Zn}$ & nd & $158.3 \mathrm{mg} \mathrm{kg}^{-1}$ \\
\hline & $\mathrm{Pb}$ & nd & $248.36 \mathrm{mg} \mathrm{kg}^{-1}$ \\
\hline & $\mathrm{Fe}$ & nd & $7643 \mathrm{mg} \mathrm{kg}^{-1}$ \\
\hline & $\mathrm{Mn}$ & $0.685 \mathrm{mg} \mathrm{L}^{-1}$ & $130.9 \mathrm{mg} \mathrm{kg}^{-1}$ \\
\hline & $\mathrm{Cd}$ & nd & nd \\
\hline & $\mathrm{Ca}$ & $144.7 \mathrm{mg} \mathrm{L}^{-1}$ & $4310 \mathrm{mg} \mathrm{kg}^{-1}$ \\
\hline
\end{tabular}

"nd: Not detected 
Table 2 The variations of AVS and SEM/AVS in sediments

\begin{tabular}{|c|c|c|c|c|}
\hline \multirow{2}{*}{$\begin{array}{l}\text { Time ( } \\
\text { day) }\end{array}$} & \multicolumn{2}{|c|}{$A V S\left(m g \mathrm{~kg}^{-1}\right)$} & \multicolumn{2}{|c|}{$\sum S E M / A V S$} \\
\hline & control & $\begin{array}{c}\text { after adding } \mathrm{Ca}\left(\mathrm{NO}_{3}\right. \\
)_{2}\end{array}$ & control & after adding $\mathrm{Ca}\left(\mathrm{NO}_{3}\right)_{2}$ \\
\hline 1 & $5767 \pm 81$ & $6144 \pm 129$ & $0.02 \pm 0.002$ & $0.02 \pm 0.002$ \\
\hline 2 & $5510 \pm 93$ & $4180 \pm 115$ & $0.02 \pm 0.001$ & $0.03 \pm 0.002$ \\
\hline 12 & $5293 \pm 64$ & $4017 \pm 96$ & $0.02 \pm 0.001$ & $0.06 \pm 0.004$ \\
\hline 26 & $5798 \pm 85$ & $942.6 \pm 56$ & $0.02 \pm 0.002$ & $0.25 \pm 0.032$ \\
\hline 33 & $5535 \pm 63$ & $887 \pm 47$ & $0.01 \pm 0.001$ & $0.32 \pm 0.023$ \\
\hline 47 & $4641 \pm 79$ & $744 \pm 54$ & $0.03 \pm 0.002$ & $0.66 \pm 0.041$ \\
\hline 61 & $4834 \pm 97$ & $722 \pm 32$ & $0.02 \pm 0.001$ & $1.23 \pm 0.097$ \\
\hline 75 & $4873 \pm 79$ & $651 \pm 25$ & $0.03 \pm 0.002$ & $1.5 \pm 0.088$ \\
\hline 89 & $4711 \pm 73$ & $479 \pm 33$ & $0.02 \pm 0.001$ & $2.87 \pm 0.127$ \\
\hline 103 & $5091 \pm 76$ & $316 \pm 23$ & $0.02 \pm 0.001$ & $6.57 \pm 0.321$ \\
\hline 131 & $4989 \pm 64$ & $238 \pm 31$ & $0.02 \pm 0.002$ & $7.45 \pm 0.373$ \\
\hline
\end{tabular}




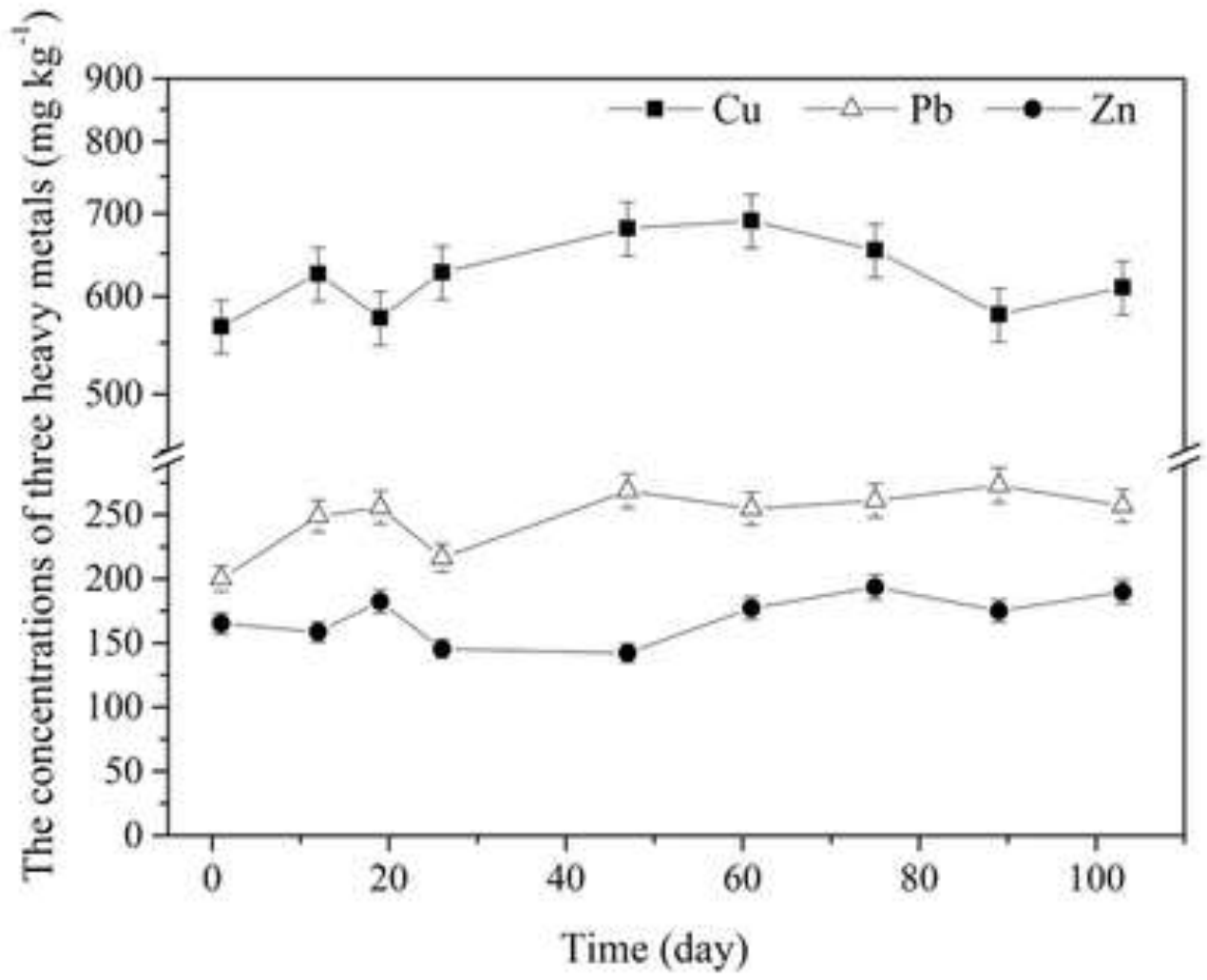

Figure 1 The concentrations of $\mathrm{Cu}, \mathrm{Pb}$ and $\mathrm{Zn}$ in the sediment 

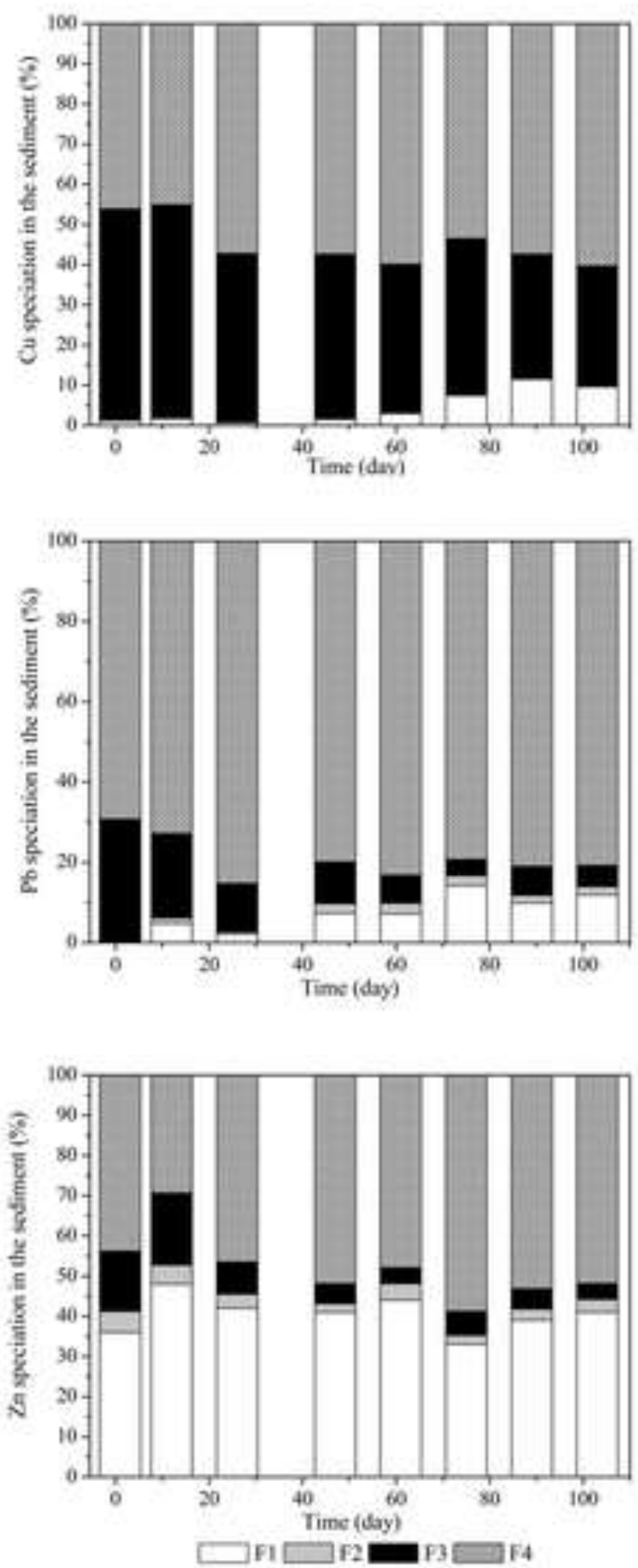

Figure 2 Speciation of $\mathrm{Cu}, \mathrm{Pb}$ and $\mathrm{Zn}$ in the sediment ( F1- acid extractable fraction, F2- iron and manganesereducible fraction, F3- oxidizable fraction and F4- residual fraction). The values are presented as mean. The 
values of Standard deviations and statistical analysis of four chemical speciation for $\mathrm{Cu}, \mathrm{Pb}$ and $\mathrm{Zn}$ were provided in Table S1, Table S2 and Table S3, respectively. 


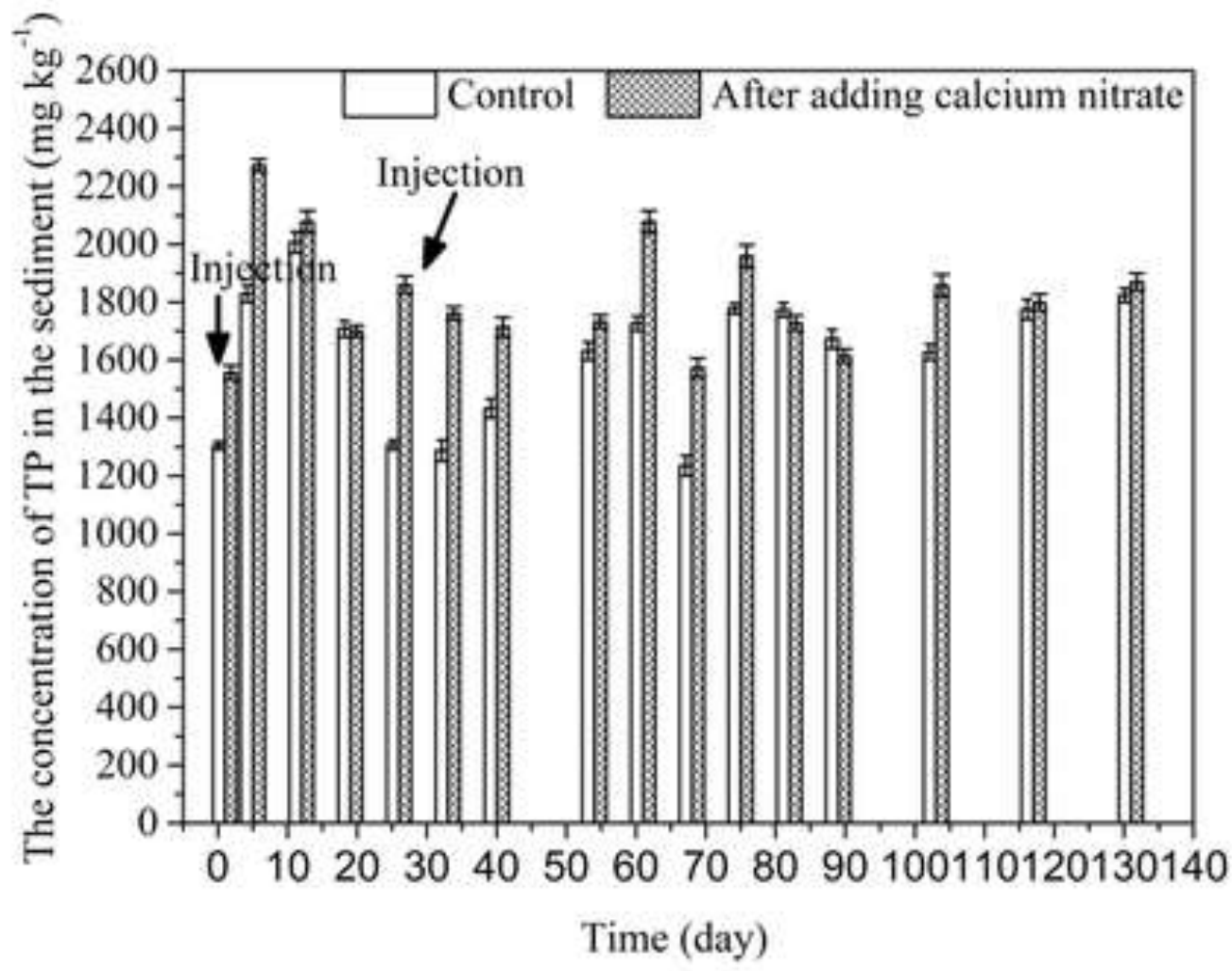

Figure 3 The TP concentration in the sediment. The arrows represent the time of adding calcium nitrate. Error bars indicate standard deviations. Asterisks indicate TP concentrations significantly different $(p<0.05)$ from untreated controls. 

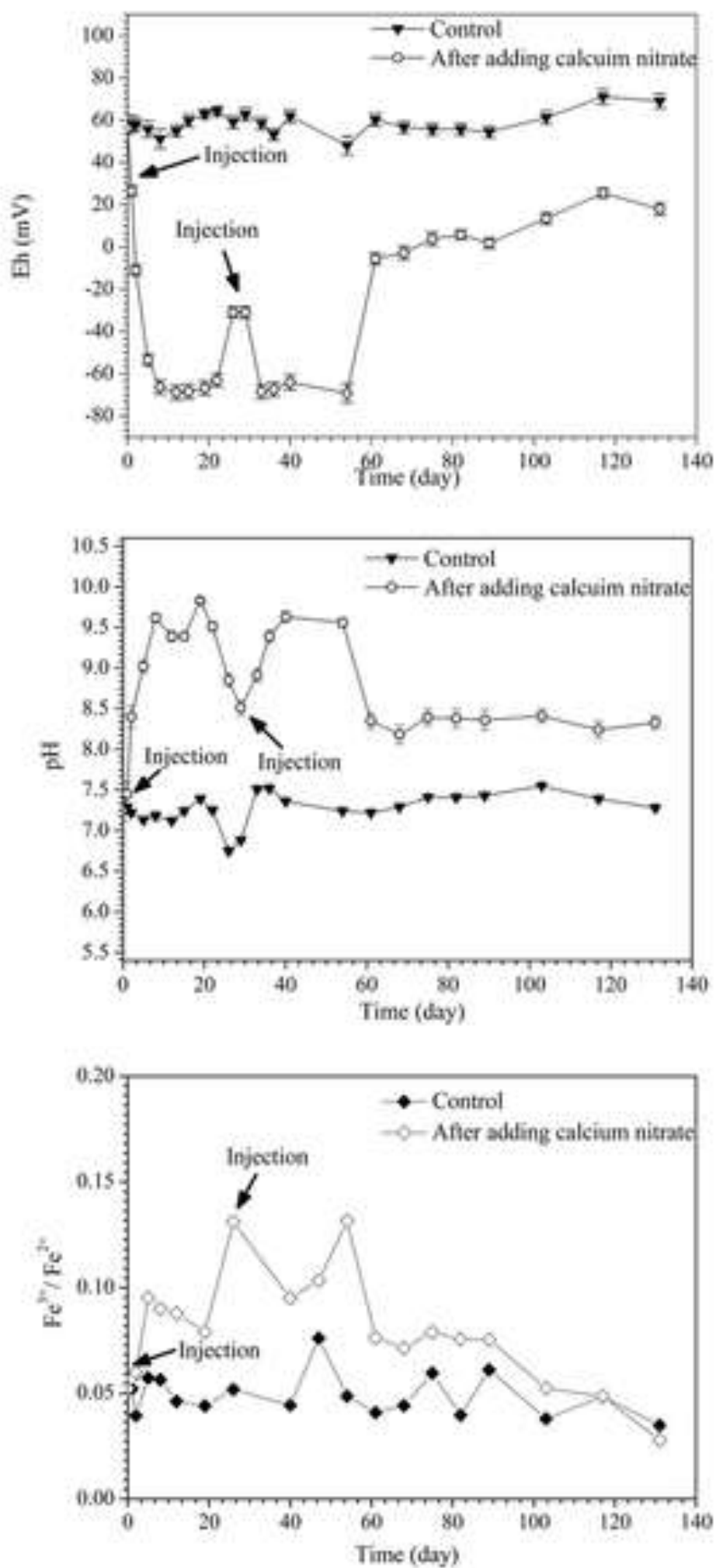

Figure 4 The effect of calcium nitrate on ORP, $\mathrm{pH}$ and $\mathrm{Fe}(\mathrm{III}) / \mathrm{Fe}(\mathrm{II})$ in the sediment. The arrowsrepresent the time of adding calcium nitrate. 


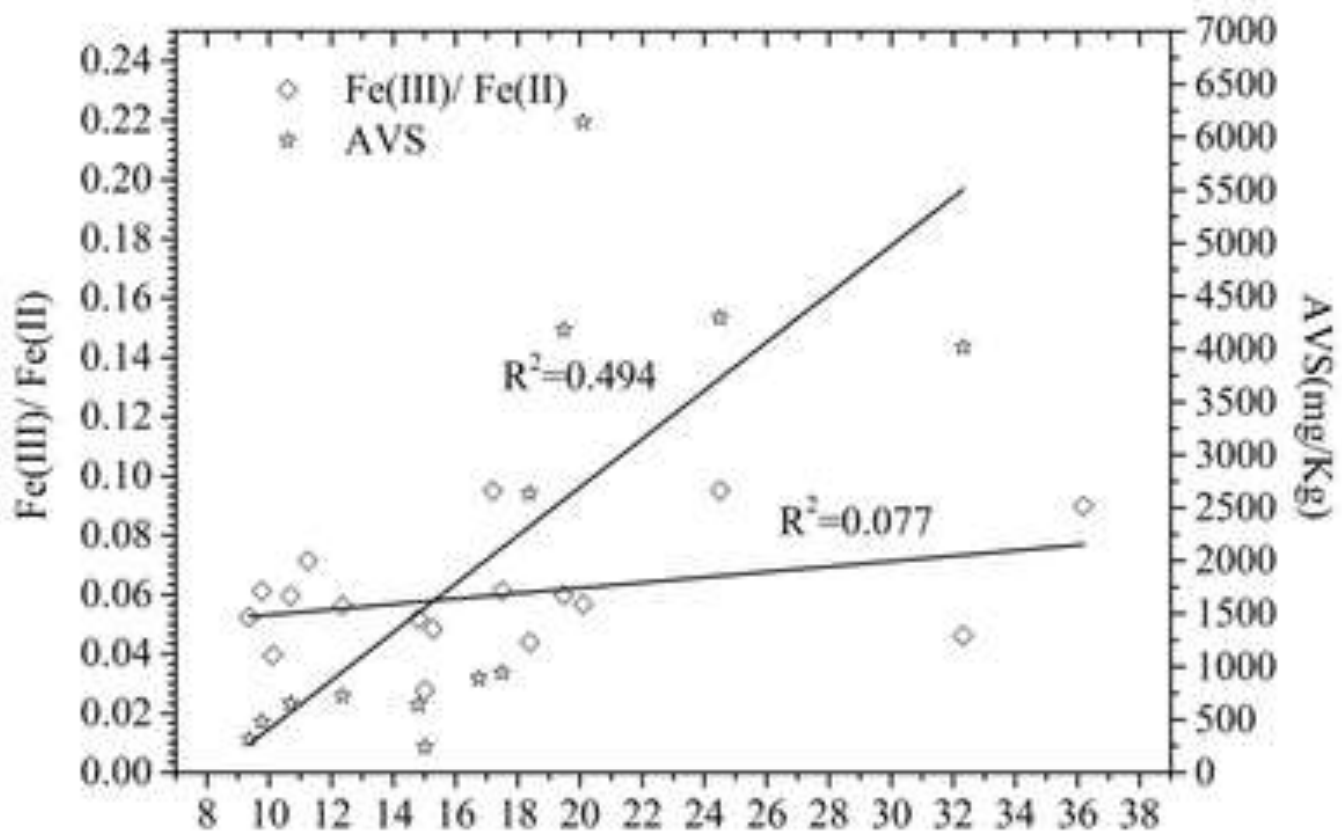

Concentration of phosphorus in interstitial water (ppm)

Figure 5 The correlations among $\mathrm{Fe}, \mathrm{S}$ and $\mathrm{P}$ in interstitial water

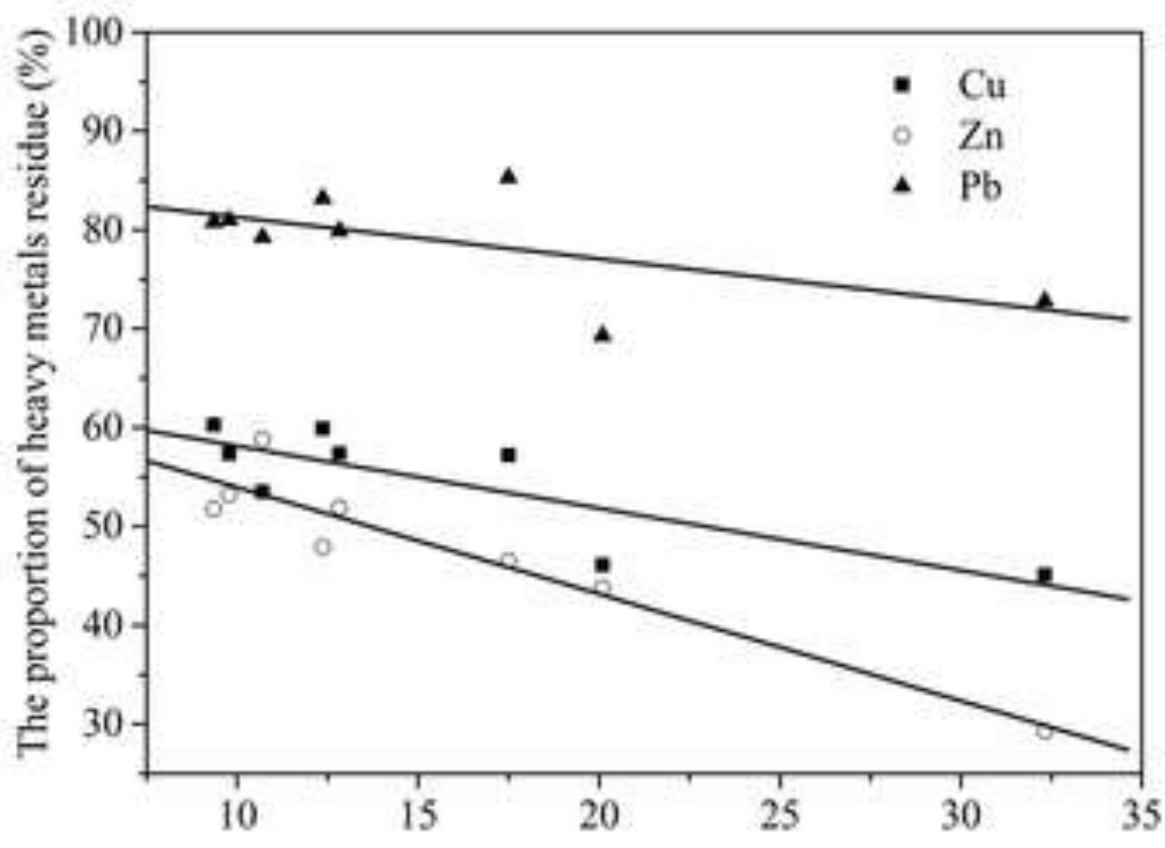

Concentration of total phosphorus in interstitial water (ppm)

Figure 6 The correlations between total phosphorus and heavy metals in interstitial water 
Supplementary files

Evaluation of heavy metals stability and phosphate mobility in the remediation of sediment by calcium nitrate Jizhi Zhou', Mingqi Zhang', Meiting Ji', Zhenghua Wang', Hao Hou', Jia Zhang', Xin Huang*,', Andrew ${\text { Hursthouse }{ }^{3.4} \text { and Guangren Qian }}^{\prime}$

1. School of Environmental and Chemical Engineering, Shanghai University, Shanghai 200444, China

2. School of Economics, Shanghai University, Shanghai 200444, China

3. Hunan Provincial Key Laboratory of Shale Gas Resource Exploitation, Hunan University of Science \&Technology, Xiangtan, 411201, Hunan, China

4. School of Science \& Sport, University of the West of Scotland, Paisley PA1 2BE, UK

*Corresponding author

*Tel: 086-021-66137748; Fax: 021-66137761; Email: huangxin2008@ shu.edu.cn

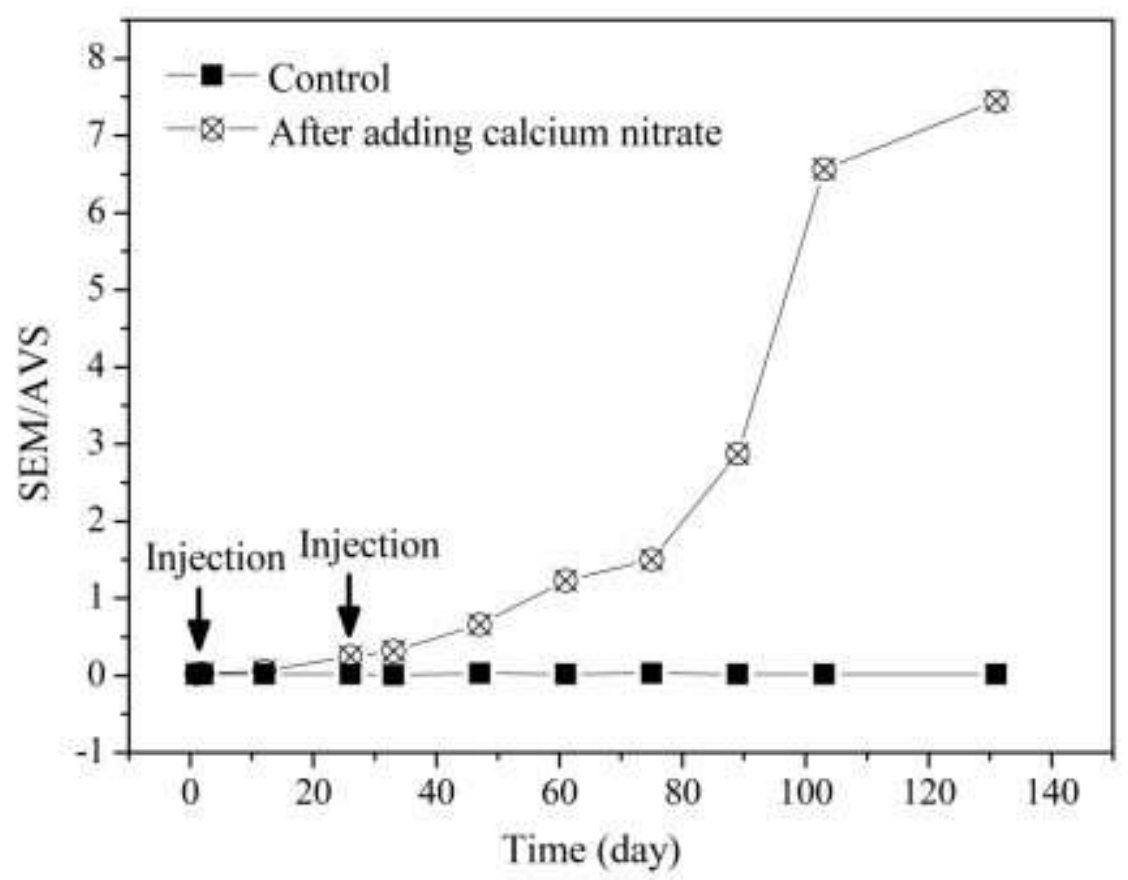

Fig. S1 Changes of SEM/AVS ratio in the sediment 


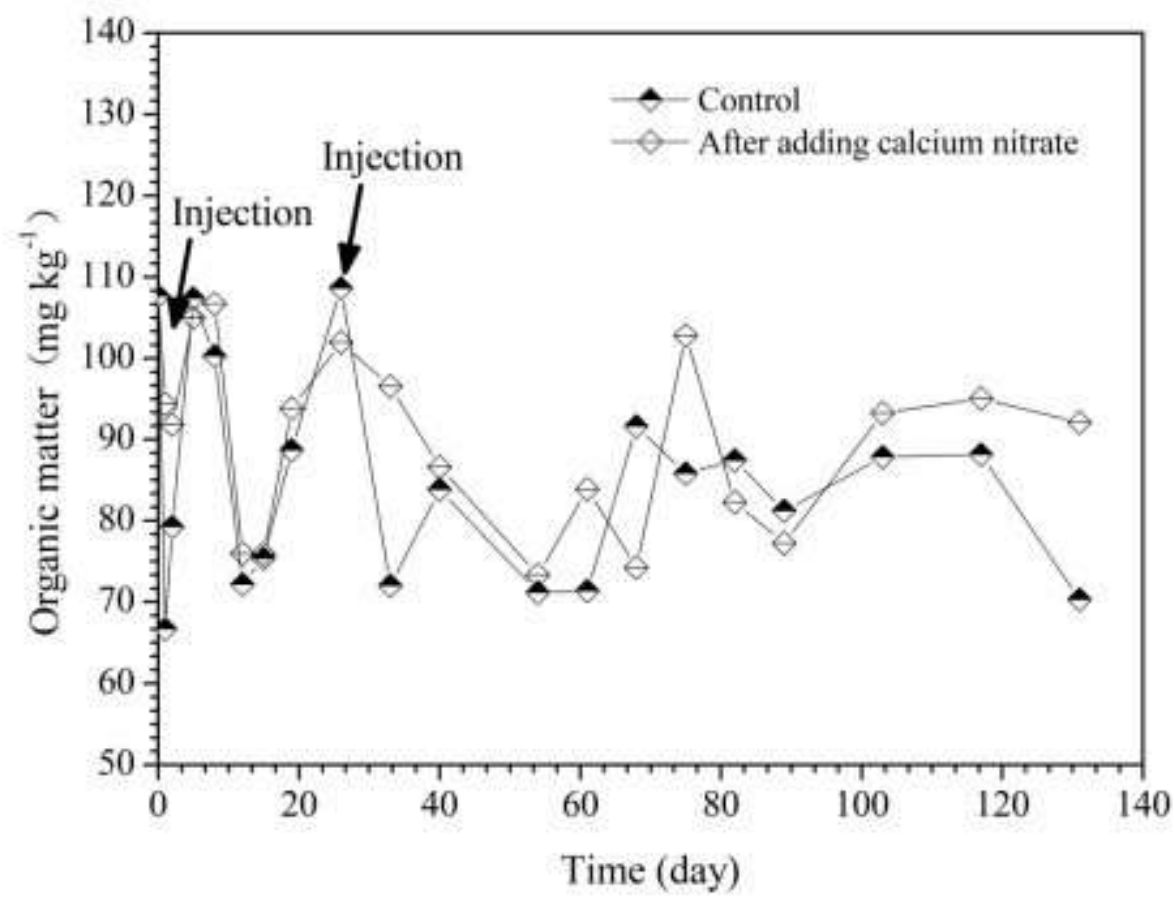

Fig. S2 Changes of organic matter in the sediment

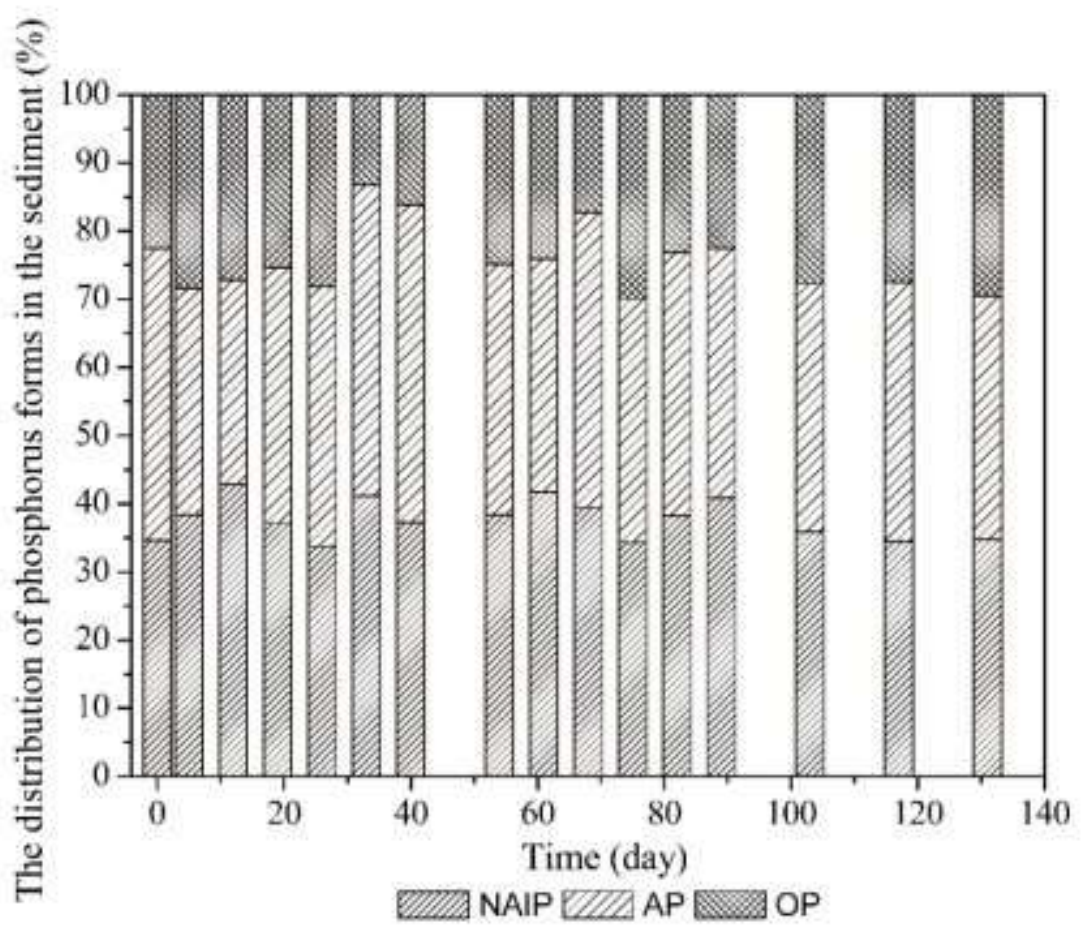

Fig. S3 Distribution and speciation of phosphorus in the sediment (NAIP: Non-apatite inorganic phosphorus, AP: Apatite phosphorus, OP: Organic phosphorus) 


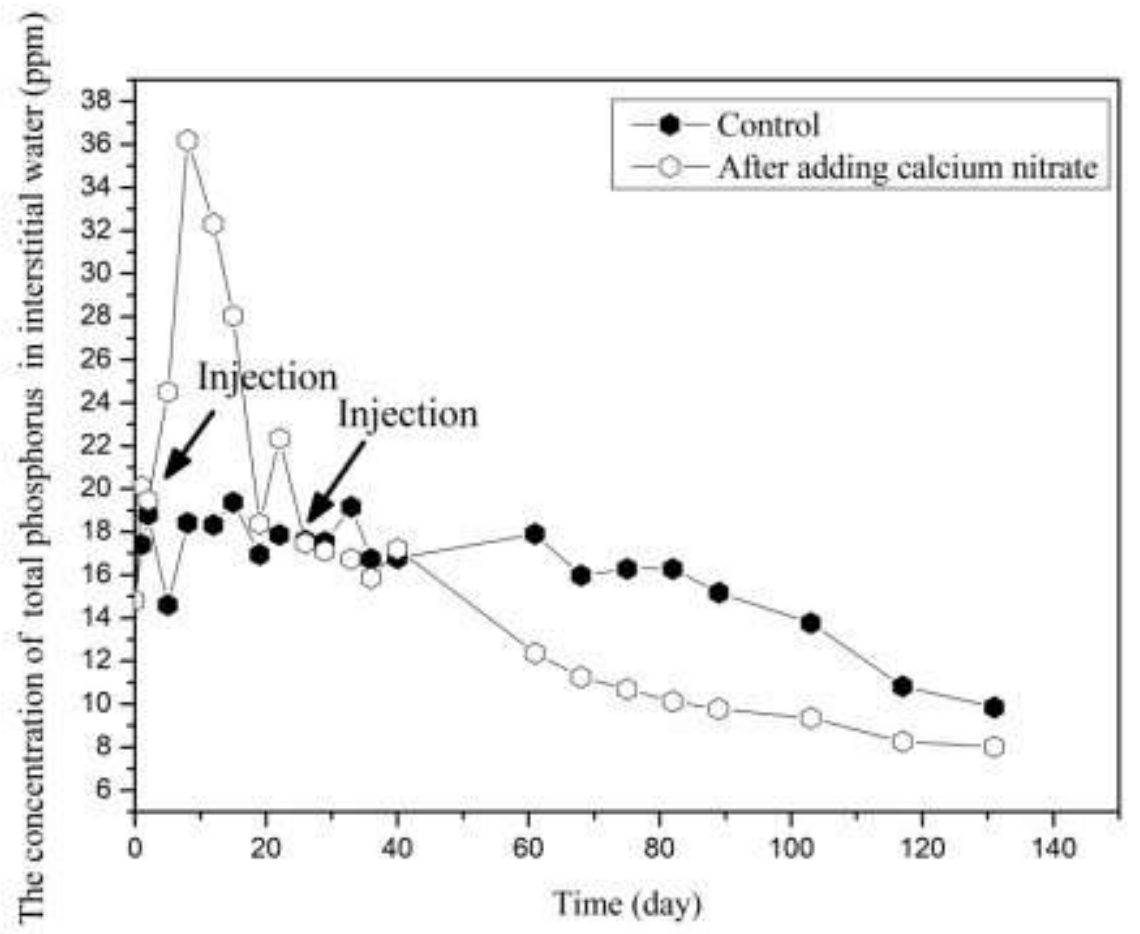

Fig. S4 Changes of total phosphorus concentration in interstitial water

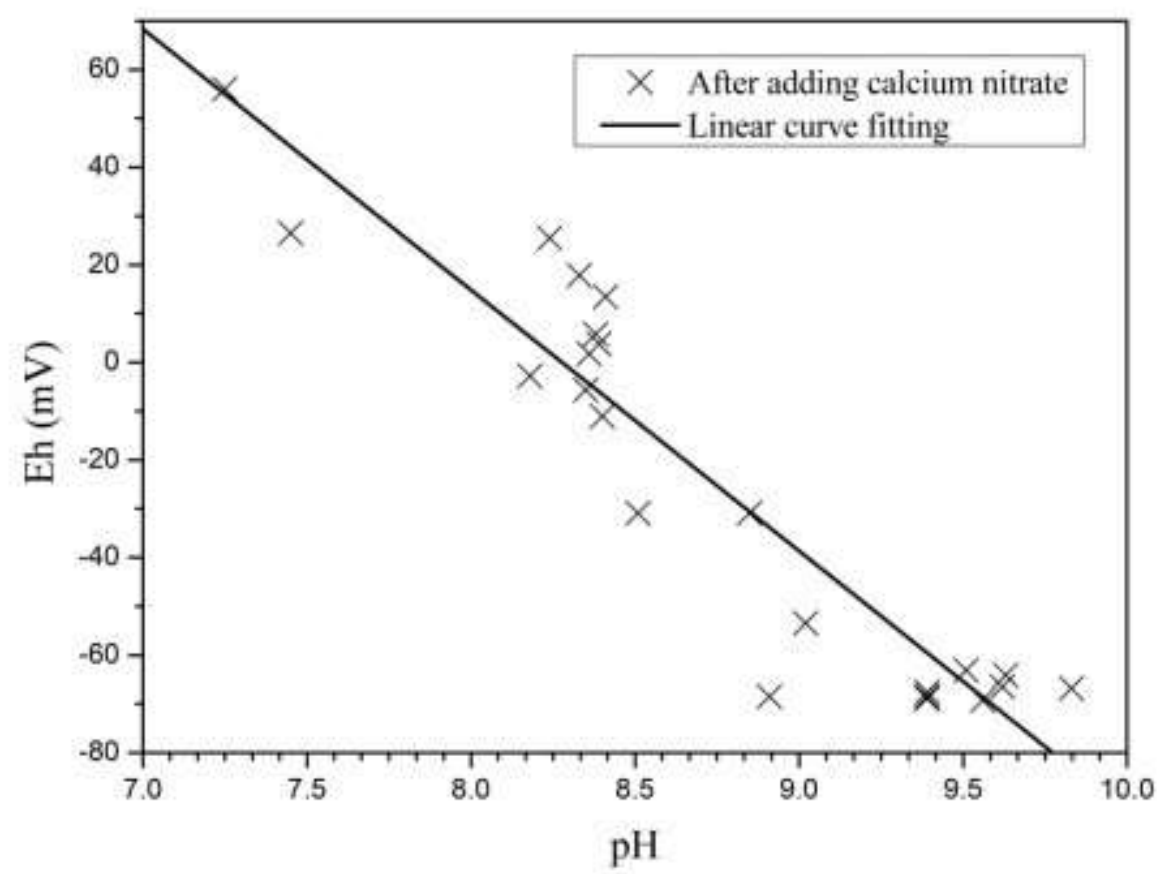

Fig. S5 Correlations between ORP and $\mathrm{pH}$ in the sediment 


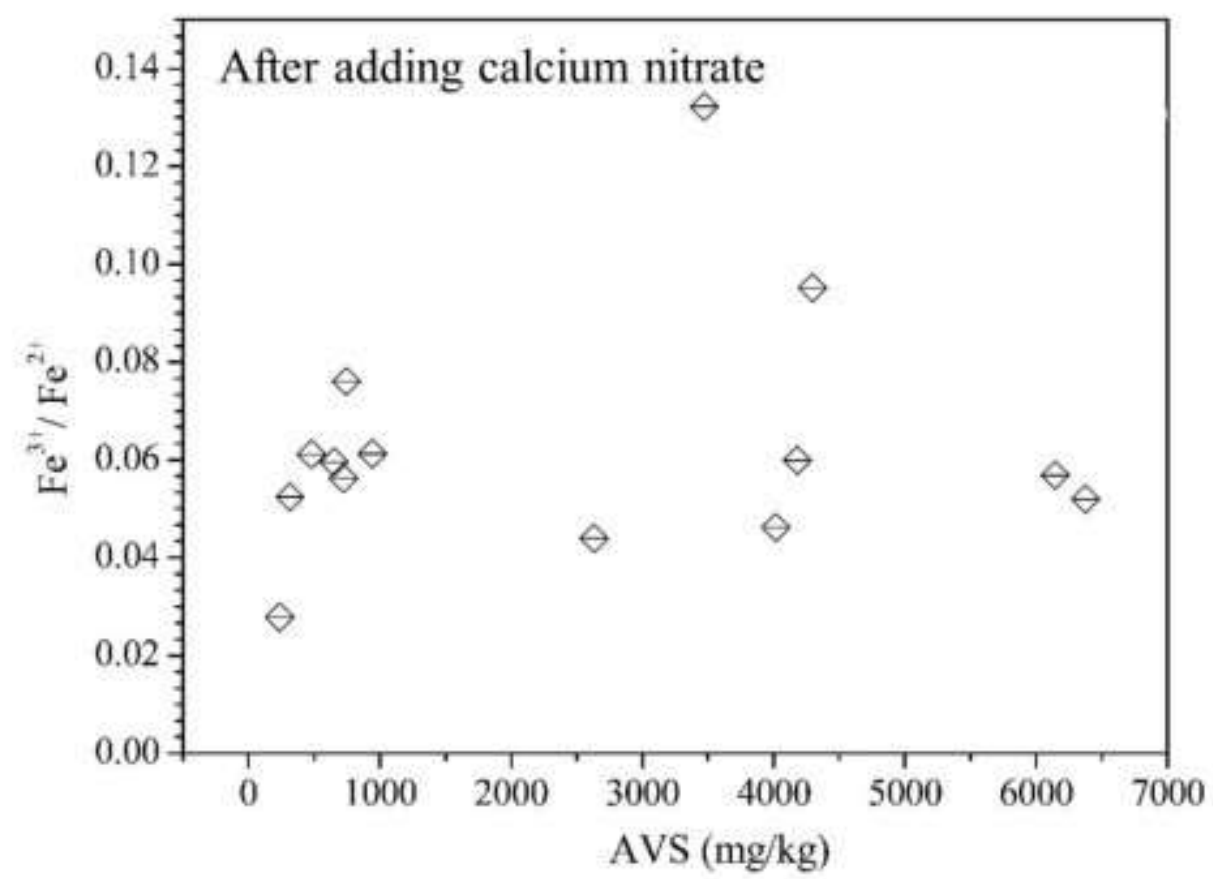

Fig. S6 Changes of correlations between Fe and $\mathrm{S}$ in the sediment

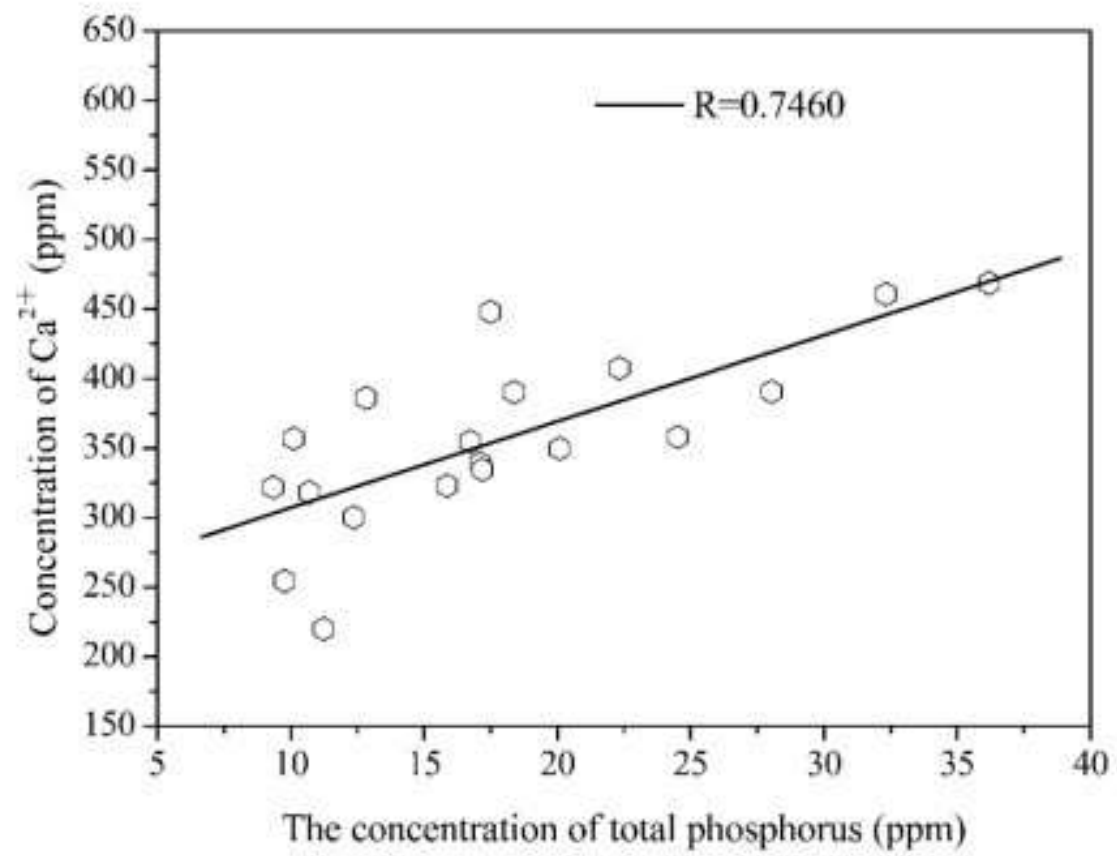

Fig. S7 Relationship between concentration of calcium and total concentration of phosphorus in interstitial water 
Table $\mathrm{S} 1 \mathrm{The}$ speciation of $\mathrm{Cu}$ in the sediment (after adding calcium nitrate) $\left(\mathrm{mg} \mathrm{kg}^{-1}\right)$

\begin{tabular}{cccccc}
\hline Time $(\mathrm{D})$ & Total & \multicolumn{1}{c}{ F1 } & \multicolumn{1}{c}{ F2 } & \multicolumn{1}{c}{ F3 } & F4 \\
\hline 1 & $567.20 \pm 28.36 \mathrm{~d}$ & $6.81 \pm 0.34 \mathrm{f}$ & $0.57 \pm 0.03 \mathrm{e}$ & $298.35 \pm 14.92 \mathrm{~b}$ & $261.48 \pm 13.07 \mathrm{f}$ \\
12 & $625.52 \pm 31.28 \mathrm{bc}$ & $10.63 \pm 0.53 \mathrm{e}$ & $1.25 \pm 0.06 \mathrm{a}$ & $331.53 \pm 16.58 \mathrm{a}$ & $282.11 \pm 14.11 \mathrm{e}$ \\
26 & $627.48 \pm 31.37 \mathrm{bc}$ & $4.39 \pm 0.22 \mathrm{~g}$ & $0.63 \pm 0.03 \mathrm{~cd}$ & $263.54 \pm 13.18 \mathrm{~d}$ & $358.92 \pm 17.95 \mathrm{c}$ \\
47 & $680.90 \pm 34.04 \mathrm{ab}$ & $10.21 \pm 0.51 \mathrm{e}$ & $0.68 \pm 0.03 \mathrm{bc}$ & $279.17 \pm 13.96 \mathrm{c}$ & $390.83 \pm 19.54 \mathrm{~b}$ \\
61 & $690.78 \pm 34.54 \mathrm{a}$ & $20.72 \pm 1.04 \mathrm{~d}$ & $0.69 \pm 0.03 \mathrm{~b}$ & $255.59 \pm 12.78 \mathrm{~d}$ & $413.78 \pm 20.69 \mathrm{a}$ \\
75 & $653.90 \pm 32.70 \mathrm{~b}$ & $48.39 \pm 2.42 \mathrm{c}$ & $0.65 \pm 0.03 \mathrm{c}$ & $255.02 \pm 12.75 \mathrm{~d}$ & $349.84 \pm 17.49 \mathrm{c}$ \\
89 & $580 \pm 29 \mathrm{~cd}$ & $66.70 \pm 3.34 \mathrm{a}$ & $0.58 \pm 0.03 \mathrm{de}$ & $179.80 \pm 8.99 \mathrm{e}$ & $332.92 \pm 16.65 \mathrm{~d}$ \\
103 & $610 \pm 30.5 \mathrm{c}$ & $58.56 \pm 2.93 \mathrm{~b}$ & $0.61 \pm 0.03 \mathrm{~d}$ & $183.00 \pm 9.15 \mathrm{e}$ & $367.83 \pm 18.39 \mathrm{c}$ \\
\hline
\end{tabular}

Table S2 The speciation of $\mathrm{Zn}$ in the sediment (after adding calcium nitrate) $\left(\mathrm{mg} \mathrm{kg}^{-1}\right)$

\begin{tabular}{lccccccccccc}
\hline Time(D) & \multicolumn{3}{c}{ Total } & \multicolumn{3}{c}{ F1 } & \multicolumn{3}{c}{ F2 } & \multicolumn{3}{c}{ F3 } & \multicolumn{1}{c}{ F4 } \\
\hline 1 & 165.22 & $\pm 8.26 \mathrm{c}$ & 59.48 & $\pm 2.97 \mathrm{~d}$ & 8.59 & $\pm 0.43 \mathrm{a}$ & 24.78 & $\pm 1.24 \mathrm{~b}$ & 72.37 & $\pm 3.62 \mathrm{e}$ \\
12 & 158.57 & $\pm 7.93 \mathrm{c}$ & 76.11 & $\pm 3.81 \mathrm{a}$ & 7.45 & $\pm 0.37 \mathrm{~b}$ & 28.54 & $\pm 1.43 \mathrm{a}$ & 46.46 & $\pm 2.32 \mathrm{~g}$ \\
26 & 145.41 & $\pm 7.27 \mathrm{~d}$ & 61.07 & $\pm 3.05 \mathrm{~cd}$ & 5.09 & $\pm 0.25 \mathrm{~d}$ & 11.63 & $\pm 0.58 \mathrm{c}$ & 67.62 & $\pm 3.38 \mathrm{f}$ \\
47 & 142.14 & $\pm 7.11 \mathrm{~d}$ & 58.28 & $\pm 2.91 \mathrm{~d}$ & 2.98 & $\pm 0.15 \mathrm{f}$ & 7.11 & $\pm 0.36 \mathrm{f}$ & 73.77 & $\pm 3.69 \mathrm{e}$ \\
61 & 177.13 & $\pm 8.86 \mathrm{~b}$ & 77.94 & $\pm 3.90 \mathrm{a}$ & 7.26 & $\pm 0.36 \mathrm{~b}$ & 7.09 & $\pm 0.35 \mathrm{f}$ & 84.84 & $\pm 4.24 \mathrm{~d}$ \\
75 & 193.59 & $\pm 9.68 \mathrm{a}$ & 63.88 & $\pm 3.19 \mathrm{c}$ & 4.26 & $\pm 0.21 \mathrm{e}$ & 11.62 & $\pm 0.58 \mathrm{c}$ & 113.83 & $\pm 5.69 \mathrm{a}$ \\
89 & 175.00 & $\pm 8.75 \mathrm{~b}$ & 68.25 & $\pm 3.41 \mathrm{~b}$ & 4.90 & $\pm 0.25 \mathrm{~d}$ & 8.75 & $\pm 0.44 \mathrm{~d}$ & 93.10 & $\pm 4.66 \mathrm{c}$ \\
103 & 190.00 & $\pm 9.50 \mathrm{a}$ & 77.90 & $\pm 3.90 \mathrm{a}$ & 6.08 & $\pm 0.30 \mathrm{c}$ & 7.60 & $\pm 0.38 \mathrm{e}$ & 98.42 & $\pm 4.92 \mathrm{~b}$ \\
\hline
\end{tabular}

*Total- total concentration of heavy metal, F1 - acid extractable fraction, $F 2$ - iron and manganese-reducible fraction, $F 3$ - oxidizable fraction and $F 4$ - residual fraction. The values are presented as mean $\pm S D$. Mean values in a column not sharing a letter are

Table $\mathrm{S} 3 \mathrm{The}$ speciation of $\mathrm{Pb}$ in the sediment (after adding calcium nitrate) $\left(\mathrm{mg} \mathrm{kg}^{-1}\right)$

\begin{tabular}{lccrlccccccc}
\hline Time(D) & \multicolumn{2}{c}{ Total } & \multicolumn{2}{c}{ F1 } & \multicolumn{3}{c}{ F2 } & \multicolumn{2}{c}{ F3 } & & F4 \\
\hline 1 & 200.20 & $\pm 10.01 \mathrm{~d}$ & 0.60 & $\pm 0.03 \mathrm{~h}$ & 0.40 & $\pm 0.02 \mathrm{e}$ & 60.46 & $\pm 3.02 \mathrm{a}$ & 138.74 & $\pm 6.94 \mathrm{~d}$ \\
12 & 248.92 & $\pm 12.45 \mathrm{~b}$ & 11.95 & $\pm 0.60 \mathrm{f}$ & 3.24 & $\pm 0.16 \mathrm{c}$ & 52.52 & $\pm 2.63 \mathrm{~b}$ & 181.21 & $\pm 9.06 \mathrm{c}$ \\
26 & 216.33 & $\pm 10.82 \mathrm{c}$ & 4.76 & $\pm 0.24 \mathrm{~g}$ & 1.08 & $\pm 0.05 \mathrm{~d}$ & 25.96 & $\pm 1.30 \mathrm{~d}$ & 184.53 & $\pm 9.23 \mathrm{c}$ \\
47 & 268.70 & $\pm 13.43 \mathrm{ab}$ & 19.61 & $\pm 0.98 \mathrm{~d}$ & 6.45 & $\pm 0.32 \mathrm{a}$ & 27.94 & $\pm 1.40 \mathrm{c}$ & 214.69 & $\pm 10.73 \mathrm{ab}$ \\
61 & 254.67 & $\pm 12.73 \mathrm{~b}$ & 18.34 & $\pm 0.92 \mathrm{e}$ & 6.62 & $\pm 0.33 \mathrm{a}$ & 17.83 & $\pm 0.89 \mathrm{f}$ & 211.89 & $\pm 10.59 \mathrm{ab}$ \\
75 & 260.99 & $\pm 13.05 \mathrm{ab}$ & 37.06 & $\pm 1.85 \mathrm{a}$ & 6.52 & $\pm 0.33 \mathrm{a}$ & 10.44 & $\pm 0.52 \mathrm{~h}$ & 206.97 & $\pm 10.35 \mathrm{~b}$
\end{tabular}




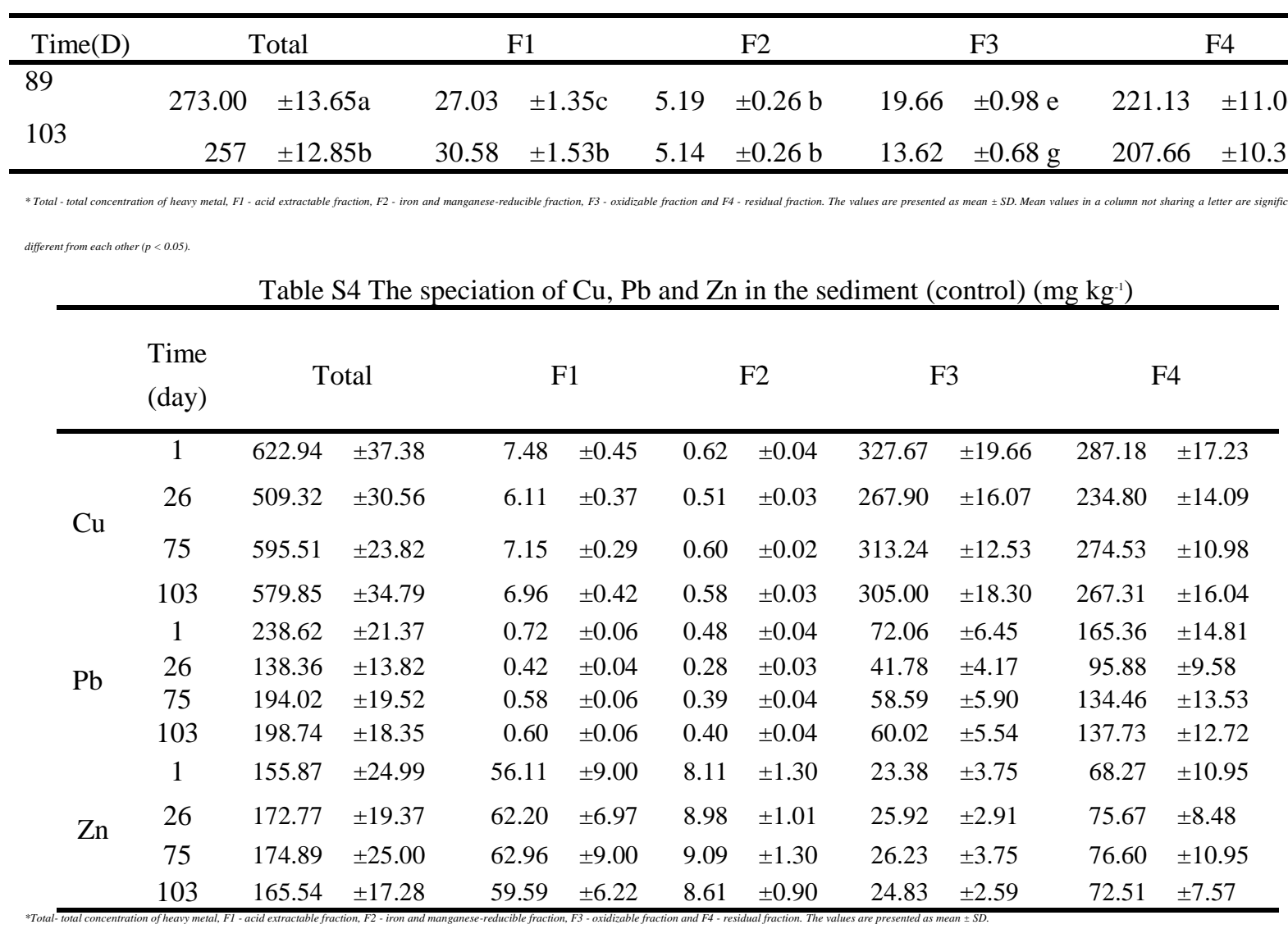

Table S5 The speciation of phosphorus in the sediment (after adding calcium nitrate) $\left(\mathrm{mg} \mathrm{kg}^{-1}\right)$

\begin{tabular}{lllllllll}
\hline Time(D) & \multicolumn{2}{c}{ Total } & \multicolumn{2}{c}{ NAIP } & & AP & & OP \\
\hline 0 & 1556 & $\pm 25 \mathrm{f}$ & 539 & $\pm 9 \mathrm{e}$ & 667 & $\pm 11 \mathrm{~d}$ & 350 & $\pm 6 \mathrm{~h}$ \\
5 & 2272 & $\pm 22 \mathrm{a}$ & 871 & $\pm 8 \mathrm{a}$ & 754 & $\pm 7 \mathrm{~b}$ & 647 & $\pm 6 \mathrm{a}$ \\
12 & 2078 & $\pm 38 \mathrm{~b}$ & 891 & $\pm 16 \mathrm{a}$ & 621 & $\pm 11 \mathrm{e}$ & 566 & $\pm 10 \mathrm{bc}$ \\
19 & 1700 & $\pm 20 \mathrm{e}$ & 631 & $\pm 7 \mathrm{~d}$ & 637 & $\pm 7 \mathrm{de}$ & 431 & $\pm 5 \mathrm{f}$ \\
26 & 1860 & $\pm 30 \mathrm{~d}$ & 627 & $\pm 10 \mathrm{~d}$ & 709 & $\pm 11 \mathrm{c}$ & 524 & $\pm 8 \mathrm{~d}$ \\
33 & 1762 & $\pm 22 \mathrm{e}$ & 724 & $\pm 9 \mathrm{~b}$ & 805 & $\pm 10 \mathrm{a}$ & 233 & $\pm 3 \mathrm{j}$ \\
40 & 1714 & $\pm 34 \mathrm{e}$ & 639 & $\pm 13 \mathrm{~cd}$ & 797 & $\pm 16 \mathrm{a}$ & 278 & $\pm 6 \mathrm{i}$ \\
54 & 1733 & $\pm 23 \mathrm{e}$ & 663 & $\pm 9 \mathrm{c}$ & 640 & $\pm 8 \mathrm{de}$ & 430 & $\pm 6 \mathrm{f}$ \\
61 & 2078 & $\pm 38 \mathrm{~b}$ & 867 & $\pm 16 \mathrm{a}$ & 710 & $\pm 13 \mathrm{c}$ & 501 & $\pm 9 \mathrm{de}$ \\
68 & 1573 & $\pm 33 \mathrm{f}$ & 619 & $\pm 13 \mathrm{~d}$ & 682 & $\pm 14 \mathrm{~cd}$ & 272 & $\pm 6 \mathrm{i}$ \\
75 & 1959 & $\pm 39 \mathrm{c}$ & 673 & $\pm 13 \mathrm{bc}$ & 700 & $\pm 14 \mathrm{~cd}$ & 586 & $\pm 12 \mathrm{~b}$ \\
82 & 1727 & $\pm 27 \mathrm{e}$ & 660 & $\pm 10 \mathrm{~cd}$ & 668 & $\pm 10 \mathrm{~d}$ & 400 & $\pm 6 \mathrm{~g}$ \\
89 & 1614 & $\pm 24 \mathrm{f}$ & 660 & $\pm 10 \mathrm{~cd}$ & 590 & $\pm 9 \mathrm{e}$ & 364 & $\pm 5 \mathrm{~h}$
\end{tabular}




\begin{tabular}{lllllllll}
\hline Time(D) & \multicolumn{2}{c}{ Total } & \multicolumn{2}{c}{ NAIP } & \multicolumn{2}{c}{ AP } & & OP \\
\hline 103 & 1858 & $\pm 38 \mathrm{~d}$ & 667 & $\pm 14 \mathrm{c}$ & 676 & $\pm 14 \mathrm{~cd}$ & 515 & $\pm 11 \mathrm{de}$ \\
117 & 1799 & $\pm 29 \mathrm{de}$ & 620 & $\pm 10 \mathrm{~d}$ & 683 & $\pm 11 \mathrm{~cd}$ & 496 & $\pm 8 \mathrm{e}$ \\
131 & 1870 & $\pm 30 \mathrm{~cd}$ & 650 & $\pm 10 \mathrm{~cd}$ & 666 & $\pm 11 \mathrm{~d}$ & 554 & $\pm 9 \mathrm{c}$ \\
\hline
\end{tabular}

*Total- total concentration of phosphorus, NAIP - Non-apatite inorganic phosphorus, AP - Apatite phosphorus, OP - Organic phosphorus). The values are presented as mean \pm SD. Mean values in a column not sharing a letter are significantly different from each other ( $P<0.05$ ). 